\title{
Global
}

Earthquake Monitoring:

\section{ITS USES, POTENTIALS,} AND SUPPORT REQUIREMENTS

Panel on Seismograph Networks

Committee on Seismology

Assembly of Mathematical and Physical Sciences

National Research Council

NATIONAL ACADEMY OF SCIENCEES

Washington, D.C.

1977 


\section{DISCLAIMER}

This report was prepared as an account of work sponsored by an agency of the United States Government. Neither the United States Government nor any agency Thereof, nor any of their employees, makes any warranty, express or implied, or assumes any legal liability or responsibility for the accuracy, completeness, or usefulness of any information, apparatus, product, or process disclosed, or represents that its use would not infringe privately owned rights. Reference herein to any specific commercial product, process, or service by trade name, trademark, manufacturer, or otherwise does not necessarily constitute or imply its endorsement, recommendation, or favoring by the United States Government or any agency thereof. The views and opinions of authors expressed herein do not necessarily state or reflect those of the United States Government or any agency thereof. 


\section{DISCLAIMER}

Portions of this document may be illegible in electronic image products. Images are produced from the best available original document. 
NOTICE: The project that is the subject of this report was approved by the Governing Board of the National Research Council, whose members are drawn from the Councils of the National Academy of :Sciences, the National Academy of Engineering, and the Institute of Medicine. The members of the Committee responsible for the report were chosen for their special competences and with regard for appropriate balance.

This report has been reviewed by a group other than the authors according to procedures approved by a Report Review Committee consisting of members of the National Academy of Sciences, the National Academy of Engineering, and the Institute of Medicine.

ISBN $0-309-02608-3$

Library of Congress Catalog Card Number 77-5219

Available from

Printing and Publishing office

National Academy of Sciences

2101 Constitution Avenue, N.W.

Washington, D.C. 20418

Printed in the United States of America 
PREFACE

The long-term development and support of permanent seismograph networks must be a responsibility of government because of the magnitude, expense, and international nature of global earthquake monitoring. But in the United States, a stable federal program for such support does not exist. The U.S. program for global seismograph networks is fragmented and suffers from the lack of a long-term funding plan, and these problems are even more serious in view of current research needs and recent technological advances in instrumentation and data processing that must be incorporated into the Worldwide Standardized Seismograph Network (WWSSN).

Global seismic networks are as basic to seismology as the telescope is to astronomy and the accelerator is to physics. Without this instrumentation, seismologists are "blind" to subsurface earth processes and properties and the very survival of the science would be threatened. Support of a modern global network of seismic stations is clearly in the national interest. In a little more than a decade, the WWSSN significantly increased our knowledge of earthquakes and of earth structure and dynamics while performing its initial mission of providing basic scientific information for the detection and identification of underground nuclear explosions anywhere in the world. These major scientific advances provide important new input toward the solutions of such national problems as the monitoring of nuclear tests, earthquake hazard reduction, understanding the origin and location of minerals and geothermal energy sources, and the siting of dams and nuclear power plants.

The Committee on Seismology has a continuing responsibility to provide scientific and technical advice to those responsible for the operation of the WWSSN and other 
government-supported networks and arrays and for the conduct of research in seismology. As part of the Committee's effort to carry out this responsibility, and in view of the long-standing problem of obtaining adequate and stable financial support for seismic data-gathering activities, it formed a Panel on Seismograph Networks to summarize and evaluate the state of the networks and arrays in the light of current and foreseeable needs of the users of seismological data and to recommend both remedial and future-directed actions to responsible government decision makers and public officials. The committee recognized that substantial changes are to be expected soon in the responsibilities of federal agencies that have supported the networks and that its study should thus be undertaken at the earliest possible time.

This report addresses the topics discussed above and presents the views of the earthquake seismologists who make up the Panel concerning improvements needed in global seismic networks if they are to be used effectively. The recommendations offered reflect these concerns, and national problems and goals were given the highest priority in the Panel's deliberations.

E. R. Engdahl, Chairman

Panel on Seismograph Networks

Committee on Seismology 
ACKNOWLEDGMENTS

This study was performed by the Panel on Seismograph Networks of the Committee on Seismology in the National Research Council's Assembly of Mathematical and Physical Sciences. The work of the Committee is supported by the Defense Advanced Research Projects Agency, the Directorate for Research Applications of the National Science Foundation, the U.S. Geological Survey, the U.S. Air Force Office of Scientific Research, the National Oceanic and Atmospheric Administration, the National Aeronautics and Space Administration, the Division of Earth Sciences of the National Science Foundation, the U.S. Nuclear Regulatory Commission, and the U.S. Energy Reseaŕch and Development Administration. The Panel wishes to express its appreciation for the interest and support of these agencies. Valuable assistance was obtained from many individuals regarding specific details of the report. In particular, Jon Peterson, Director of the USGS Albuquerque Seismological Laboratory, provided information about network operations and support. 
PANEL ON

SEISMOGRAPH NETWORKS

E. R. Engdahl, NOAA/University of Colorado, Chairman

Shelton S. Alexander, The Pennsylvania State University

Michael A. Chinnery, Lincoln Laboratory, Massachusetts Institute of Technology

Adam Dziewonski, Harvard University

J. Freeman Gilbert, University of California, San Diego at La Jolla

Donald V. Helmberger, California Institute of Technology

Bryan L. Isacks, Cornell University

\section{Liaison Members}

John R. Filson, Advanced Research Projects Agency Edward A. Flinn, National Aeronautics and Space Administration

Robert M. Hamilton, U.S. Geological Survey

Roy E. Hanson, National Science Foundation

James F. Lander, National Oceanic and Atmospheric Administration

\section{Staff}

Joseph W. Berg, Jr., Executive Secretary

Albert N. Bove, Staff officer 
J. Freeman Gilbert, University of California, San Diego at La Jolla, Chairman

Lloyd S. Cluff, Woodward-Clyde Consultants

E. R. Engdahl, NOAA/University of Colorado

John I. Ewing, Woods Hole Oceanographic Institution

William J. Hall, University of Illinois

David D. Jackson, University of California at Los Angeles

Lane R. Johnson, University of California at Berkeley

Sidney Kaufman, Cornell University

Carl Kisslinger, University of Colorado

Robert P. Meyer, University of Wisconsin

otto $W$. Nuttli, st. Louis University

C. H. Scholz, Lamont-Doherty Geological Observatory

Don L. Anderson, California Institute of Technology, ex officio

\section{Liaison Members}

William J. Best, U.S. Air Force Office of Scientific Research

Edward A. Flinn, National Aeronautics and Space Administration

Robert M. Hamilton, U.S. Geological Survey

Roy E. Hanson; National Science Foundation

Jerry Harbour, U.S. Nuclear Regulatory Conmission

George A. Kolstad, U.S. Energy Research and Development

Administration

James F. Lander, National Oceanic and Atmospheric Administration

Carl F. Romney, Advanced Research Projeçts Agency

John B. Scalzi, National Science Foundation 
Joseph W. Siry, National Aeronautics and Space Administration

Robert E. Wallace, U.S. Geological Survey

\section{Staff}

Joseph W. Berg, Jr., Executive Secretary

Albert N. Bove, Staff officer 
CONTENTS

1 Summary and Major Recommendations 1

2 Introduction 5

3 Early History of Seismic Networks and Instrumentation

4 The Worldwide Standardized Seismograph Network

Origin and Description, 11; Capabilities and Accomplishments, 13; Support, 20

5 New Developments and Capabilities

High-Gain Long-Period System, 24; Seismic Research Observatories, 24; Abbreviated Seismic Research Observatories, 27; Arrays, 27; Data Storage and Distribution, 31; International Deployment of Accelerometers, 32; Potential for Very-Long-Period Measurements, 33; Administration and Support of Networks, 34; The Need for Portable Instruments, 35; Space-Related Studies, 35; Ocean-Bottom Seismographs, 36; Calibration, 37; The Need for On-Scale Recording, 39

6 Improved Worldwide Standardized Seismograph Network

Description, 41; Data Exchange, 44; Summary, 44

7 International Aspects 
8 Data Handling, Processing, and User Services

Data Handling and Processing, 50; The Need for

Regional Research Centers, 52; User Services, 54

9 Support for the Improved Worldwide Standardized Seismograph Network

Bibliography

Glossary

63

Appendix A. Research Directions

Appendix B. International Comment on the Worldwide Standardized Seismograph Network:

Integrated Networks and User Services 
A great earthquake in central China in A.D. 1556 took approximately 830,000 human lives--a staggering toll from a single spasm of the earth lasting only a few minutes. Until 1976, this was by far the greatest number of earthquake casualties in any year in all recorded history. It appears that 1976 will rival 1556 in human deaths from earthquakes around the world, with a total of approximately 700,000. It has been reported, unofficially but reliably, * that approximately 655,000 lives were lost in the T'ang-shan, China, earthquake of July.27, 1976, and there were 40,000 more earthquake deaths in 1976 in Guatemala, New Guinea, Turkey, Italy, and the Philippines. Hundreds of thousands of others were injured or left homeless, and the destruction of property, industry, and public facilities was enormous. Clearly, even in today's technologically advanced world, we are not free from the prospect of disaster when great natural forces are released.

Our rapidly expanding world population and its increasingly complex social and economic structures have many needs and problems. We are increasingly occupied with the search for new fuel and mineral resources in the earth. We are more and more plagued with the problem of safe disposal of immense volumes of the waste materials of our civilization--some of them potentially very dangerous to human, animal, and plant life over vast areas of the land and oceans.

The Worldwide Standardized Seismograph Network (WWSSN) has contributed basic data for at least three major developments in earth science--the detection and identification

${ }^{\star}$ The Economist, January 8, 1977, p. 13, and other sources. 
of underground nuclear explosions, the concept of plate tectonics, and the growing capability to predict earthquakes. And now, further developments in the science and its technology promise newer research horizons. The WWSSN has functioned admirably since its inception about 15 years ago, even though financial support has been marginal for the last decade. The Network's current status and its future are uncertain. Attention to this problem and appropriate action are needed now.

In view of the vital role that the WWSSN has played in the past and of its potential for making vital and unique contributions to geophysics in the future, the Panel submits the following recommendation as a minimal requirement for continuing the advancement of the science of seismology and its capacity to help resolve many human problems (see p. 22):

Recommendation 1 Stable funding in the amount of at least $\$ 860,000$ should be established to assure (a) continuing operation of the WWSSN as a basic research facility for U.S. investigators; (b) continuing maintenance and appropriate upgrading of the WWSSN; and (c) suitable data organization, storage, retrieval, and distribution facilities.

New advances in instrumental and recording capabilities have provided a vastly increased dynamic range for earthquake-wave measurements (several orders of magnitude) and a greatly improved capability to analyze digital data by means of high-speed computers. These developments can revolutionize our understanding of the physical properties and structure of the earth and lead to new insights into the genesis and emplacement of mineral resources and the nature and prediction of earthquake-related hazards.

New or improved seismic stations have been installed at many locations around the world as components of special networks; many of the new stations are at the locations of WWSSN stations. The new stations have the improved capability of a digital-data-recording system and improved instrumental characteristics, and the networks provide wider global coverage.

These new stations are the Seismic Research Observatories (SRO'S); the Abbreviated Seismic Research Observatories (ASRO's); the High-Gain Long-Period (HGLP) stations, which were installed by the Defense Advanced Research Projects Agency (DARPA); and the stations installed under the International Deployment of Accelerometers (IDA) 
project, which has been supported by the National Science Foundation and private funds. The establishment of these new stations has been envisaged as upgrading of the WWSSN, and, to date, they have been used only for special research studies.

The time is at hand to take full advantage of the new, improved seismic stations by combining them, under a specific program and under a single agency for management purposes, into an improved WWSSN. Such a network can provide U.S. investigators in particular and investigators throughout the world in general with a seismological research capability far beyond any that exists today. An interagency committee composed of representatives from DARPA, NSF, NOAA, USGS, and OMB should be established to provide a mechanism for appropriate transfer of management responsibilities.

The potential of such an improved system to make possible otherwise impossible studies of global and regional earth structure and of source mechanisms is immeasurable. The Panel believes that with this new system a new era in seismological services would emerge, involving, among other capabilities, routine announcements of new and more definitive earthquake parameters (location, depth, size, stress release, for example). In view of this new potential, the following recommendation by the Panel is clearly within the national interest (see pp. 3435 and 56):

Recommendation 2 (a) Stable funding should be established within the U.S. Geological Survey to continue operation, maintenance, and improvement of the HGLP, SRO, ASRO, and IDA seismograph stations: Further, about 50 WWSSN stations should be upgraded to include digital recording capability.

(b) The National Oceanographic and Atmospheric Administration should provide facilities for the organization, storage, retrieval, and distribution of digital data from the above observatories.

By combining the new stations into an improved global network, as recommended above, investigators will have a new level of technical capability far above that available now, but many researchers will need help in learning how to use the new digital data. To achieve this new level of earthquake-research capability, the Panel offers the following recommendation (see comprehensive discussions on pp. 52-53) : 
Recommendation 3 Regional research centers should be established at existing facilities to provide a library of digital seismic data, access to modern computer facilities, required software for processing data, and a support staff.

The Panel has looked at new areas of research, and the one that stands out as a frontier is the ocean bottom. The two thirds of the earth that is covered by ocean waters is essentially virgin territory for earthquake seismologists, and we would expect important new discoveries from studies of earthquakes recorded by instruments on the bottoms of the oceans. The technology of self-contained, free-drop, ocean-bottom seismograph capsules has advanced so that operating times as long as a year are feasible. In addition, more permanent oceanbottom stations are certainly possible utilizing tethered buoys, acoustic data links, and oceanic telephone and telegraph cables. Data from ocean-bottom stations would greatly extend our knowledge of earth gravity, load and tilt tides, and other infraseismic phenomena as a minimum. The results of these studies would be important to $a^{\prime}$ large segment of the earth-science community, including geodesists and oceanographers. The Panel submits the following recommendation to enable future investigation of this frontier of first-order importance (see p. 38):

Recommendation 4 A comprehensive effort should be made to determine the feasibility of an extensive, long-term program in ocean-bottom seismology.

The text contains several additional recommendations concerning the following:

Portable broadband seismographs ( $p$. 35)

Space-related studies (pp. 35-36)

Instrument calibration ( $p$. 39)

International cooperation (pp. 46-48)

User services (pp. 53-55)

Funding of facilities (pp. 56-58) 


\section{INTRODUCTION}

Based on nearly a century of experience, we know that global networks of seismic stations are essential to studies of such deep earth structures as the core-mantle boundary and mantle inhomogeneities and of many local and regional aspects of earthquakes, such as fault mechanisms. The results of such studies are the scientific underpinning for an understanding of the causes of earthquakes, the genesis and emplacement of primary mineral deposits, and many other earth phenomena. At present we have, and we have had for some 15 years, an excellent global seismic network, the Worldwide Standardized Seismograph Network (WWSSN), which has done an admirable job of providing needed basic data. But there are many new problems, and the technology to tackle them with is now available. This is the time, therefore, to go ahead with the needed network improvements and to get on with the studies needed to attack critical problems. A major aim of this report is to encourage action in this direction.

At present, we glean at most about 25 percent of the total information contained in WWSSN seismograms, because of instrumental deficiencies and the current method of data presentation. However, the improvements made in instrumentation in recent years have made possible more complete analysis of the entire signal from an earthquake. The following are but a few of the research areas that could be more effectively attacked if these improvements are made in our network capability: the mechanism of earth rupture (faulting); inhomogeneities of the earth; estimation of ground motion of engineering interest, including the siting of nuclear power plants; free oscillations of the earth; spatial and temporal distribution of release of stress in the earth; estimation of better earth models; better definition of earthquake source 


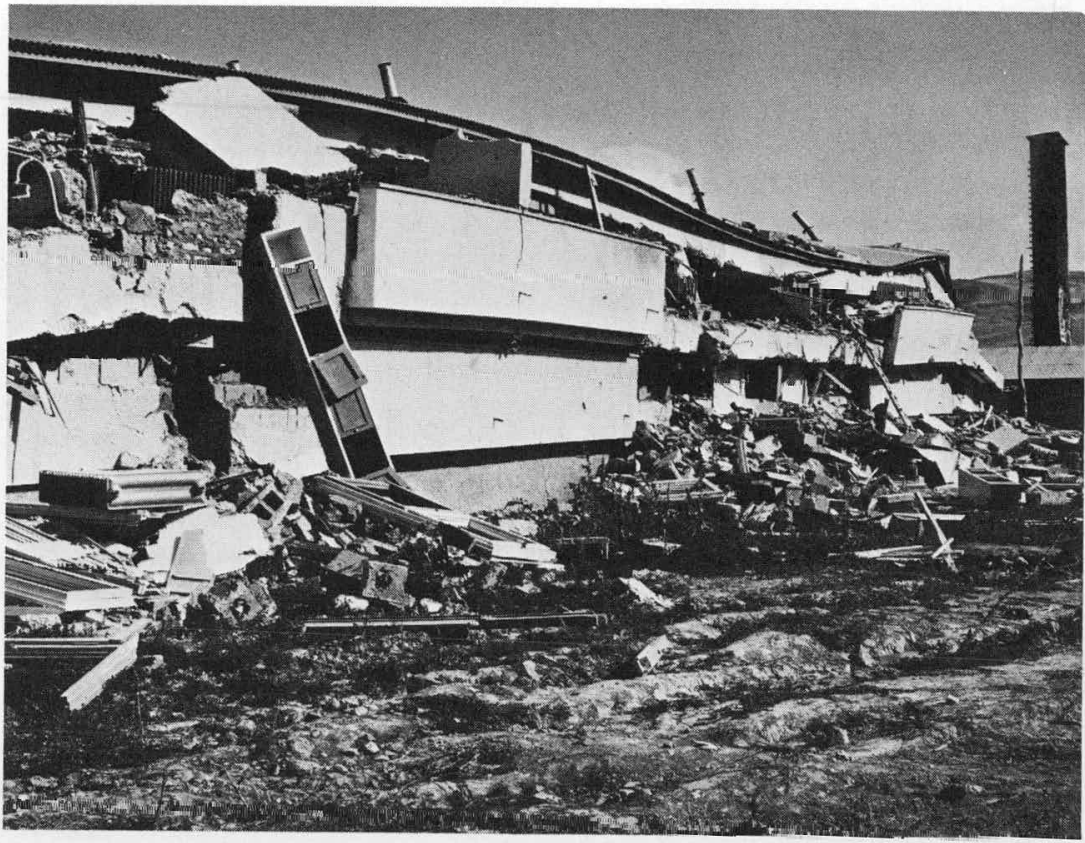

(a)

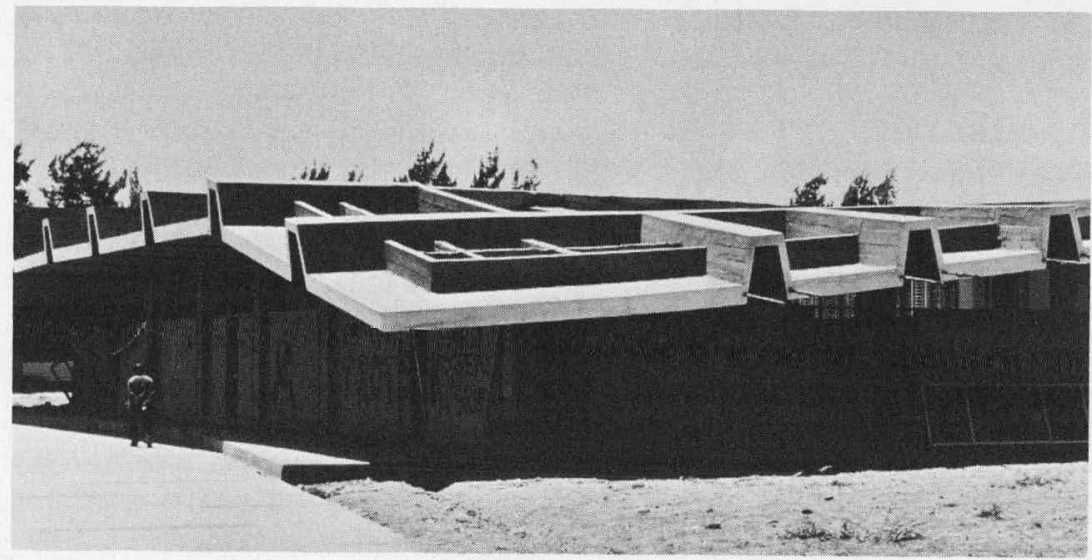

FIGURE 1 (a) Damage to school at Varto, Turkey, from (b) earthquake on August 19, 1966. (Photo U.S. Geological Survey, R. E. Wallace.) (b) Sagging roof due to column failure at the Agricultural University from the earthquake at Lima, Peru, on October 3, 1974. (Photo L. A. Wyllie, Jr.) 
parameters such as depth and size; and new definition of waveforms.

A strenuous and comprehensive research effort in the areas given above is certainly in the national interest, since at least 14 federal agencies depend on seismological information in the discharge of their national responsibilities. Moreover, many major industries--petroleum, electric power (nuclear in particular), housing (and land use in general), mining, construction, and insurance, for example--would benefit directly from improved fundamental knowledge of earthquake sources and occurrences and of the general and detailed structure and dynamics of the earth.

Seismologists of the United States have long cooperated with those of other countries through exchange of earthquake data and research results. Such exchanges are necessary, since earthquakes occur in many parts of the earth and in many countries, large earthquakes are infrequent, data from many observation points are needed to solve most problems, and there is a universal desire to mitigate the devastating effects of earthquakes wherever they strike (see Figure 1). It is clear that global cooperation must continue. 


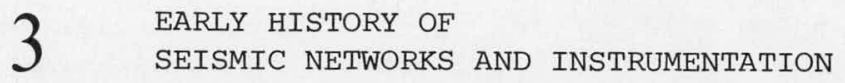

During the first 60 years of this century, several groups of seismologists, essentially independently, established and operated sets of seismograph stations equipped with similar types of instruments. These sets of stations were the forerunners of the Worldwide Standardized Seismograph Network (WWSSN) and other more sophisticated networks of recent years. A notable early global effort was the seismological program of the Jesuit colleges and universities, beginning in 1900 and including their creation of the Jesuit Seismological Association in 1925. Some processed information was collected and analyzed in their center at Saint Louis University. This effort offered the first model of a coordinated observatory network providing broad geographic coverage. Many national networks, such as that of the Coast and Geodetic Survey in the United States, and some regional networks were operated by universities and other institutions.

Rapid improvement in instrumentation followed Galitzin's application in 1912 of the electromagnetic transducer and galvanometric recording to the seismograph. Galitzin instruments, especially a version modified by Wilip to improve stability and provide linearity of response, became the primary equipment in many observatories (see Figure 2). Other important advances in instrumentation were the WoodAnderson torsion seismograph (1925), the Benioff quartzrod strain seismograph (1935), the variable-reluctance transducer adapted for seismograph applications by Benioff in 1932, and the application by LaCoste in 1935 of the zero-length spring to systems suitable for detecting longperiod vertical motions.

In spite of these early advances in instrumentation, a fundamental requirement of a good seismographic observatory, accurate and reliable timing, was not met until 


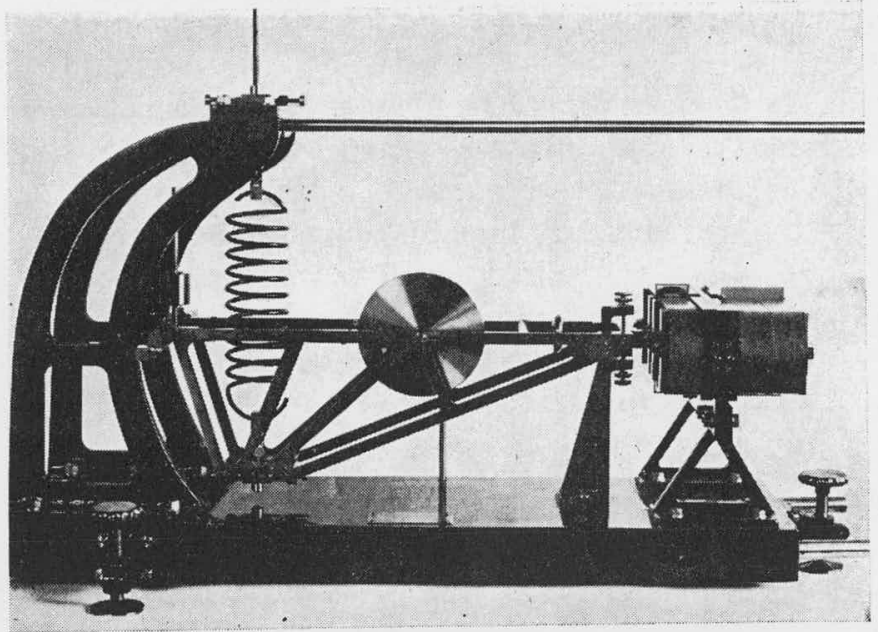

FIGURE 2 Galitzin vertical-component seismograph as manufactured by the Cambridge Instrument Company and installed at Georgetown University after World War I. (Appears on p. 163 of When the Earth Quakes by James B. Macelwane, S.J., 1947. Courtesy of Bruce Publishing Company.)

after World War II, when crystal clocks became readily available. Moreover, at the end of World War II most of the world's seismological observatories still lacked properly calibrated instrument systems with uniform response characteristics. A few individual stations did have calibrated systems, however; and special, long-period seismographs were installed in 1956-1957, in widely separated places, by the Lamont Geological Observatory of Columbia University for use in the International Geophysical Year program. These stations provided valuable experience that was exploited later when Project VELA Uniform established the WWSSN.

VELA Uniform was conceived in 1958 by the Panel on Seismic Improvement, appointed by the Special Assistant to the President of the United States for Science and Technology at the request of the Department of state in connection with the nuclear test ban negotiations. VELA Uniform required that a capability be developed to identify underground nuclear explosions. Before VELA, seismology was still in a relatively primitive state, and basic upgrading was needed. It depended then primarily on a 
handful of dedicated workers, usually with minimal resources, and on the early instruments, which were adequate only for the study of travel times of seismic waves, of amplitudes of short-period phases, and, in some cases, of surface waves with periods as long as a few minutes. 


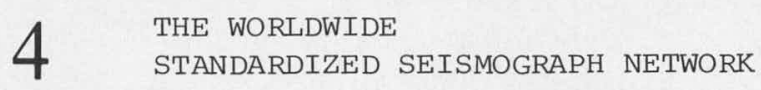

\section{ORIGIN AND DESCRIPTION}

The Worldwide Standardized Seismograph Network (WWSSN) was begun in the early $1960^{\prime} \mathrm{s}$ as a system designed to greatly expand routine observations of seismic events, to provide a standardized, well-calibrated response, and to provide versatile research capabilities. Responsibility for the installation and management of the network, supported by Department of Defense funds, was assigned to the Coast and Geodetic Survey of the Department of Commerce, a federal agency with years of experience in the operation of conventional seismic observatories. In 1972, responsibility for operation and maintenance of the WWSSN was transferred to the U.S. Geological Survey.

The Coast and Geodetic Survey was guided in the design and installation of the WWSSN by a special committee of the National Research Council. The committee's strategy for the network encompassed several main points. The instruments were to be of a reliable, proven type that could conveniently monitor a broad portion of the seismic spectrum and that required no extensive further development. To suppress the high level of background microseisms at periods of about 3 to $9 \mathrm{sec}$, it was decided to separate the frequency spectrum into two bands. Six seismometers are operated at each standard station: one vertical and two orthogonally oriented horizontals for monitoring the short-period spectrum, and a similar set for the long-period spectrum. The free periods of the pendulums are $1 \mathrm{sec}$ and either 15 or $30 \mathrm{sec}$. The periods of the galvanometers are $0.75 \mathrm{sec}$ for the short-period and $100 \mathrm{sec}$ for the long-period instruments. Recording is photographic, with drum rates of $60 \mathrm{~mm} / \mathrm{min}$ for shortperiod and 15 or $30 \mathrm{~mm} / \mathrm{min}$ for long-period records. Special 
care is exercised to maintain synchronous records through accurate timing. A crystal clock accurate to 1 part in $10^{7}$ controls the recording-drum rate and the time-marking device. In addition, radio time from the standard time broadcast is impressed automatically on the records every 12 hours. Storage batteries will operate the system for 8 hours in the event of power failure. The electrical system is designed to operate over a wide range of input voltages at frequencies of 50 to $60 \mathrm{~Hz}$ (see Figure 3).

A unique feature of the system is its standardized response. A simple switching mechanism can vary the

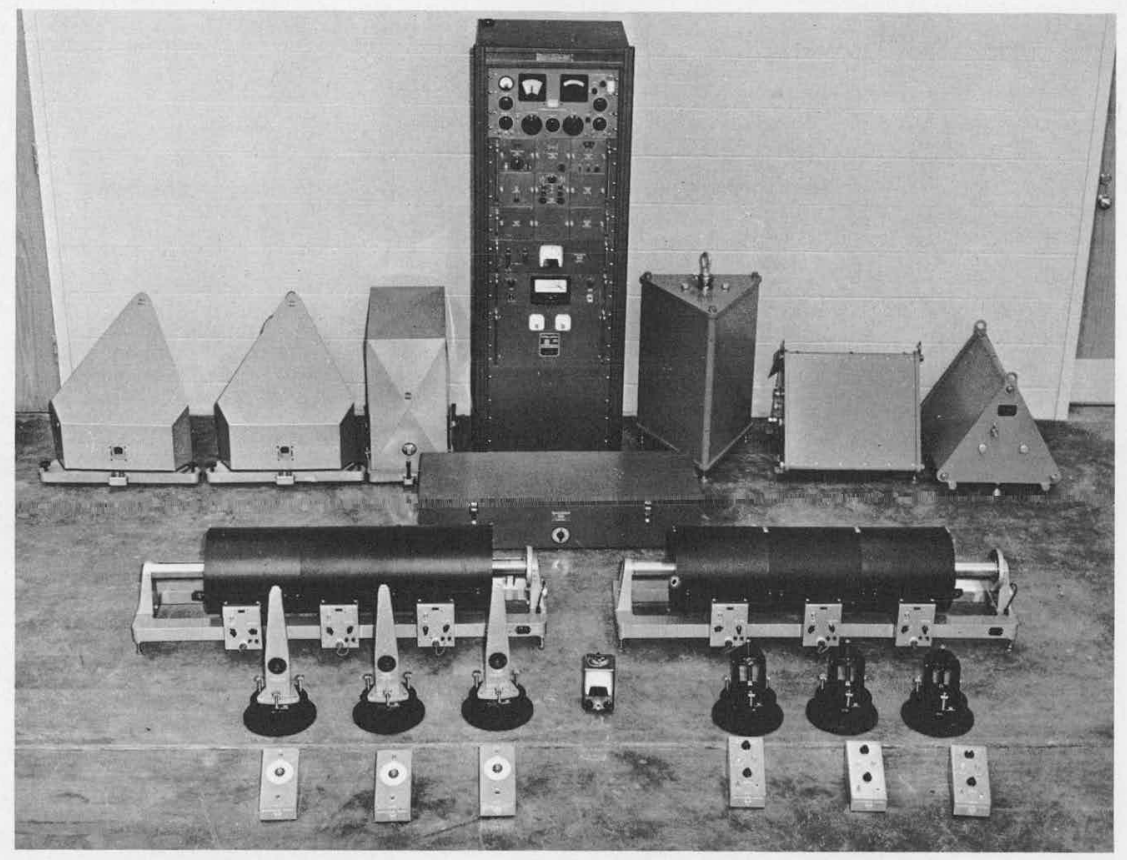

FIGURE 3 Components of the WWSSN station. Encased longperiod seismometers are shown in the upper left and longperiod photographic recording equipment in the lower left; encased short-period seismometers are shown in the upper right and short-period photographic recording equipment in the lower right. The instrument rack in the center contains a crystal-controlled clock for timing, the calibration instrumentation calibration system, and other electronic gear. The contact printer used to duplicate seismograms is shown as a rectangular box at the base of the rack. (Photo U.S. Geological Survey, Jon Peterson.) 
magnification of the short-period system, operating at a period of $1 \mathrm{sec}$, from 3125 to 400,000 in 6-decibel steps without significantly changing the shape of the response curve. Similarly, the long-period magnification for the 15-sec period ranges from 750 to 6000. A simple calibration pulse impressed at the beginning and the end of each record permits the seismologist to determine the exact frequency response of each instrument and to make quantitative comparisons among seismograms from anywhere in the network. This refinement had never before been widely achieved in the seismometry of network systems.

One hundred and twenty-three stations were established originally throughout the world, primarily at institutions that had demonstrated a continuing interest in seismology or where there appeared to be great promise for the development of a research program; some stations were established at geographic locations of special interest or of low background noise. The present configuration of the WWSSN is shown in Figure 4.

Concurrently with installation of the recording equipment, facilities for copying and distribution were established in Washington, D.C. This responsibility, and the facilities, were later transferred to Asheville, North Carolina, and eventually to Boulder, Colorado, the present location of the Environmental Data Service (EDS) of the National Oceanic and Atmospheric Administration (NOAA). The size and shape of the seismograms required the development of a special microfilming system that has performed very effectively and reliably to date.

\section{CAPABILITIES AND ACCOMPLISHMENTS}

The WWSSN soon became the most widely used seismological research network in the world, by both U.S. and foreign investigators. Within the seismological community there is general agreement that the WWSSN has been an outstanding success as a research tool (see Appendix B) as well as an effective stimulant to seismic studies at a number of institutions previously without modern equipment. Data from the WWSSN played a key role in seismology's contribution to the testing and development of the concepts of sea-floor spreading, continental drift, and plate tectonics, as well as the detection and identification of underground nuclear explosions. During the 1960's, the number of earthquakes routinely located, and the precision of those locations, increased by a factor of 3 to 5 . This was an 


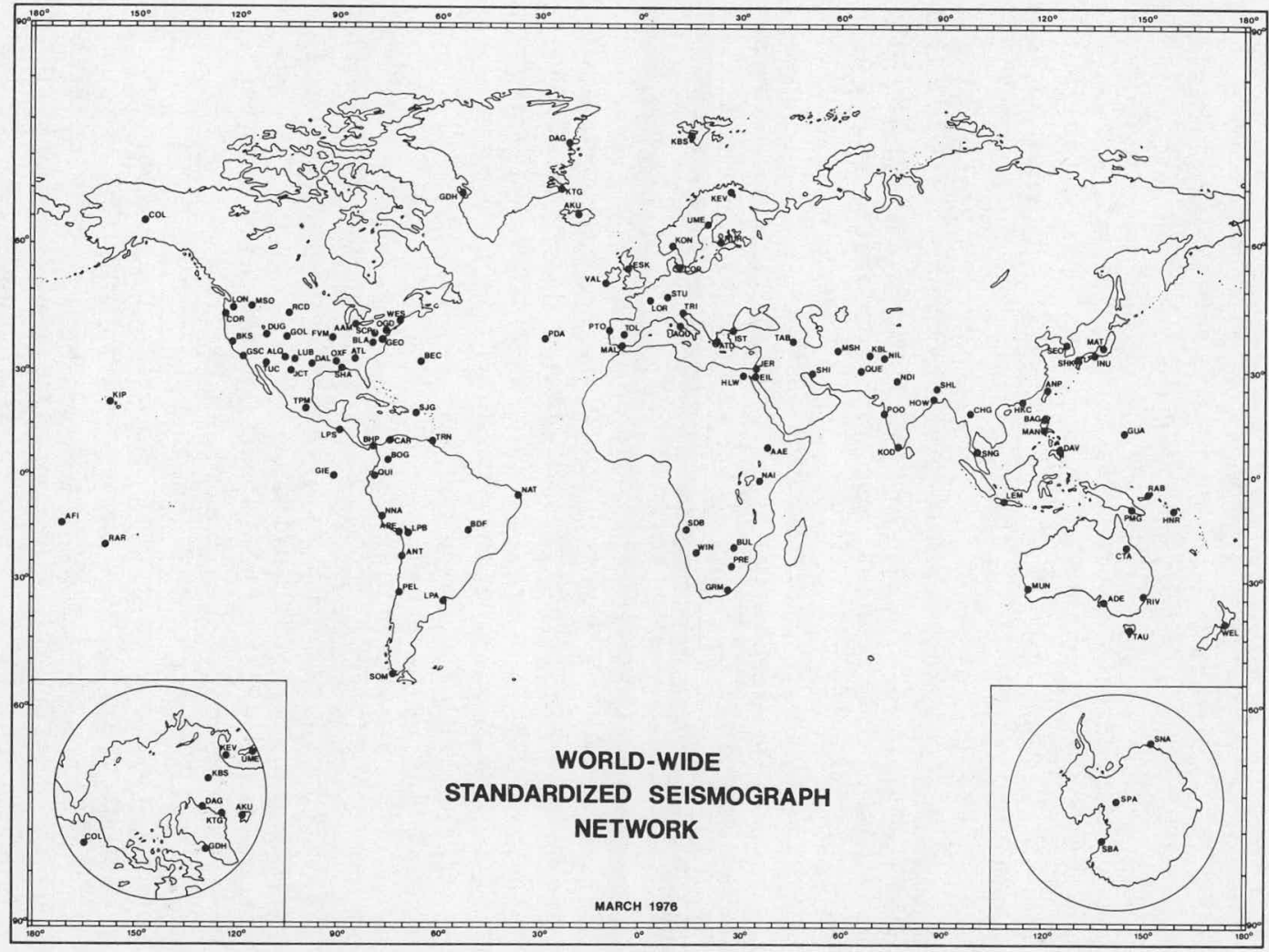

FIGURE 4 WWSSN station locations with identifying call letters. (Photo cour... U.S. Geological Survey.) 
important development, which greatly improved knowledge of seismicity and made correlation of geology and seismicity much more precise and informative. The resulting consistent global pattern of seismicity and the nearly continuous, narrow major seismic belts outlining the stable areas define the boundaries of the lithospheric plates postulated by the concept of plate tectonics (see Figure 5).

The simple fault-origin model of earthquakes predicts a definite pattern of radiation of seismic waves, and observations of this pattern can be used to derive the orientation of the fault plane and direction of relative motion (focal mechanism). Data from the WWSSN are vital to the determination of focal mechanisms, since data from stations covering a large part of the earth's surface are needed for this purpose. When WWSSN data became available, inconsistencies in focal-mechanism determinations dropped from about 20 percent to less than 1 percent. Focalmechanism determinations for shallow shocks in island arcs, ocean ridges, and fracture zones provide the major part of the seismological data in support of plate tectonics. These data have shown, for example, that the transformfault hypothesis, which predicts a direction of relative motion along ocean fracture zones exactly opposite to that of the conventional interpretation, is indeed correct. A key finding in the problem of the driving mechanism of the plate motions came from a comprehensive study of the focal mechanism of the intermediate and deep earthquakes in island arcs throughout the world. It was found that the pattern of stresses at intermediate depths is consistent with sinking of the lithospheric slab under its own weight beneath island arcs, with resistance to further sinking at greater depth (see Figure 6).

Recently, several new techniques have been used to determine parameters of the seismic source, such as seismic moment, fault dimension, stress, and stress drop. In the exploration of this promising new direction, data from the WWSSN have been and will continue to be crucial.

The uniform response of the WWSSN instruments has made possible studies of wave propagation, and WWSSN data were used to map areas in which plates of lithosphere were judged to be continuous or discontinuous on the basis of the efficiency of propagation of certain types of seismic waves through those areas. With few exceptions, the results support the simple model of plate tectonics. Before the existence of the WWSSN, there was no possibility of a global study and, hence, of interpreting the fundamental global pattern of wave propagation. 


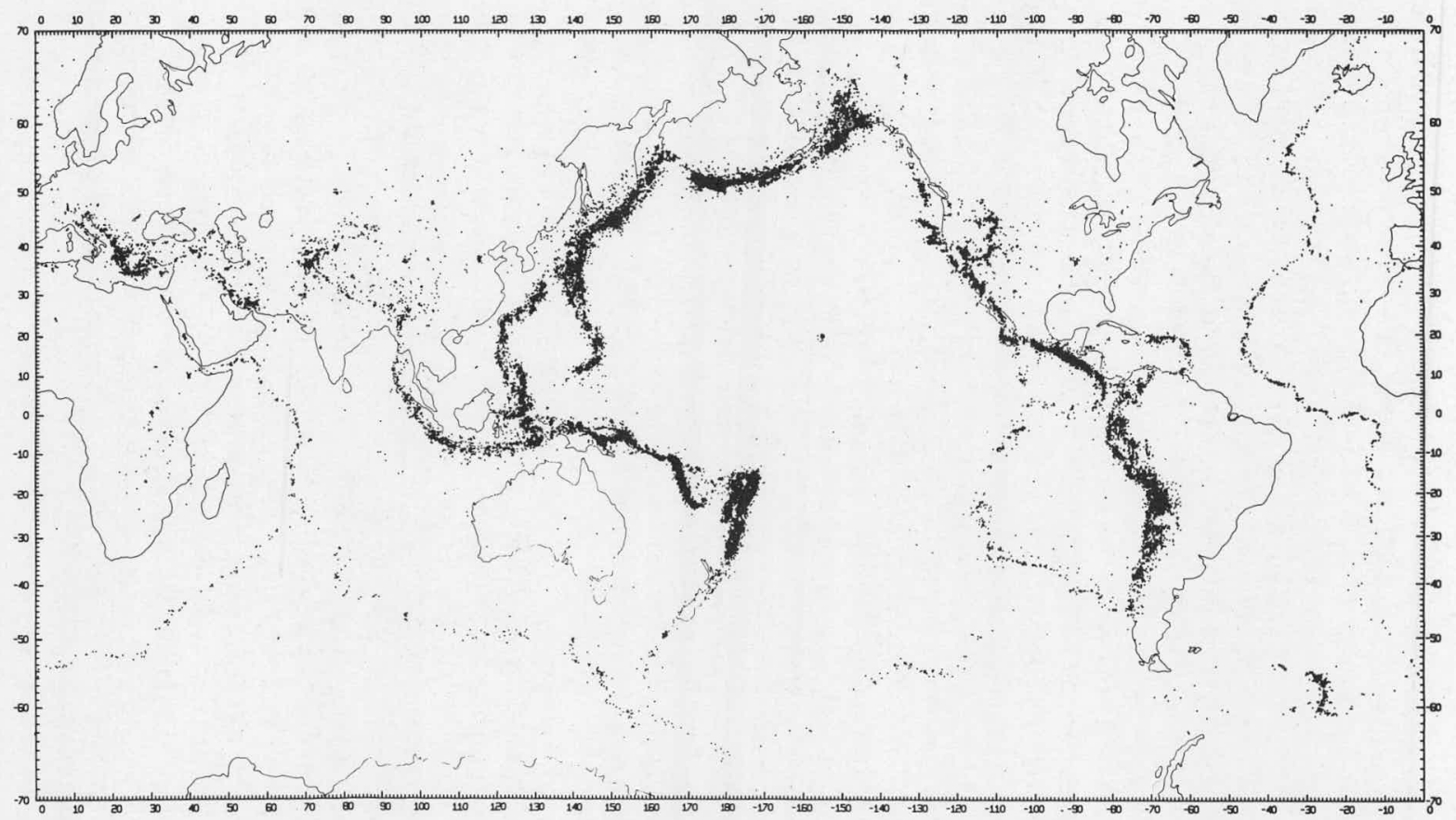

FIGURE 5 Seismicity of the earth, 1961-1967, ESSA, CGS epicenters. The dark bands on the map consist of many thousands of small dots, each representing the epicenter of an earthquake. The definition of plate boundaries can be inferred from the bands. (From M. Baragangi and J. Dorman, Bull. Seismol. SoC. Am. 59, No. 1.) 


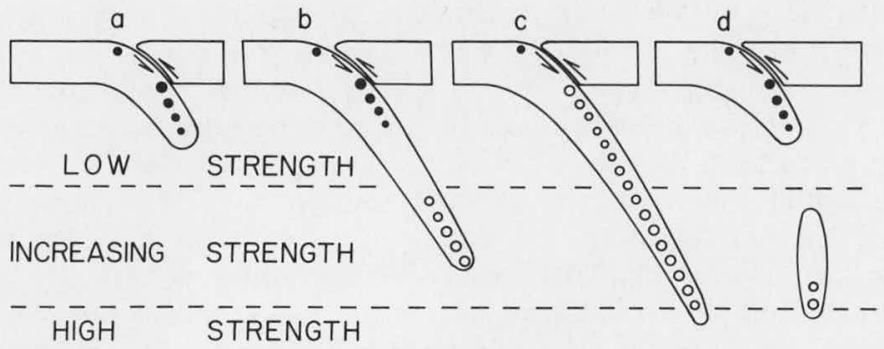

FIGURE 6 Model showing plausible distributions of stresses within slabs where gravitational forces act on excess mass within the slabs. A filled circle represents down-dip extension, an unfilled circle represents down-dip compression, and the size of the circle qualitatively indicates the relative amount of seismic activity. In (a) the slab sinks into the asthenosphere, and the load of excess mass is mainly supported by forces applied to the slab above the sinking portion; in (b) the slab penetrates stronger material, and part of the load is supported from below, part from above; the stress changes from extension to compression as a function of depth. In (c) the entire load is supported from below, and the slab is under compression throughout. In (d) a piece has broken off. A gap in seismicity as a function of depth would be expected for (b) and (d), whereas no deep earthquakes occur beneath (a). The horizontal dashed lines in the figures indicate possible phase changes in the upper mantle near $350-400 \mathrm{~km}$ and $650-700$ km. (Figure after B. Isacks and P. Ward, Rev. Geophys. Space Phys. 9, No. 1, February 1971, copyrighted by American Geophysical Union.)

Free oscillations of the earth have been detected and their characteristic frequencies measured from the spectra of WWSSN recordings even at periods as long as $1500 \mathrm{sec}$. These oscillations are largely unaffected by local structure, so that observations of their spectral energy distribution gives information about the radial distribution of elastic parameters and density with depth, averaged over the whole earth. Despite the poor response and small signal-to-noise ratio of WWSSN instruments in this verylong-period range, the data from a great many WWSSN stations used simultaneously as a global array has increased the number of observed free-oscillation modes to over 1000 . 
Thus, it can be seen that the WWSSN has provided crucial information on seismicity, focal mechanisms, wave propagation, and other characteristics of the earth. This information has been valuable to the geophysical community in the broadest sense.

The WWSSN has continued to provide data for numerous studies of geologic phenomena within the earth, particularly for those studies that bear on the seismicity of the earth and on its temporal variations. These studies are vital, moreover, to our understanding of the serious earthquake hazard confronting a large portion of our nation, and the need for this understanding grows as the nation's population density and the complexity of society grow (see Figure 7). Destructive earthquakes originate with forces and processes deep within the earth, and the WWSSN is a vital tool in our efforts to understand these forces and processes. A better appreciation of earthquake characteristics such as depths, dimensions, and stresses is useful, if not essential, to an understanding of the conditions that exist in fault zones. Hence, the potential for developing a capability for meaningful earthquake prediction depends significantly on data from the WWSSN. In another area of current major concern--the location and delineation of energy resources--the Network may be useful in many ways, for example, analysis of delays in the arrival times of seismic waves as determined from the network may help in the location of geothermal sources. Knowledge bearing on the siting of nuclear reactors is also an important product of studies based on data from the Network. In plate tectonics, the Network has provided data that have made possible an integrated earth-science approach to an understanding of basic earth processes and have contributed toward a new dimension, geodynamics, that must be included in our search for mineral and energy resources.

In recent years, significant progress has been made in the theoretical and numerical aspects of the study of earthquake mechanisms and in the investigation of earth structure. Observations used in such analyses have been derived almost exclusively from the WWSSN, and now the technology is available to improve and to augment existing instrumentation for these and newer studies. First, there are requirements for data in digital form, which is now accomplished by manual conversion of analog WWSSN records. This process is time-consuming, not very accurate, suffers from a small dynamic range, and in terms of manpower requirements alone severely limits the research potential. 


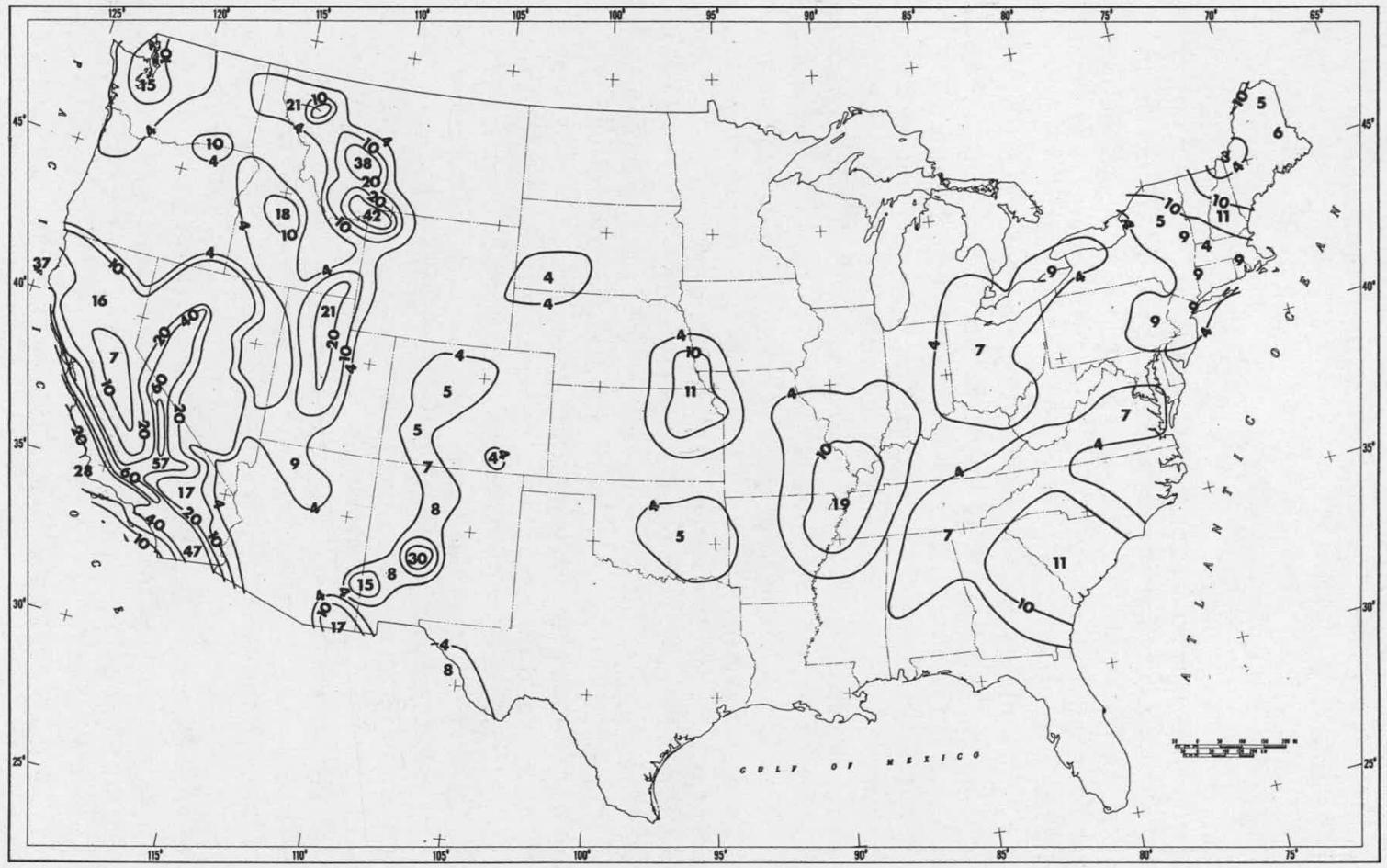

FIGURE 7 Preliminary map of horizontal acceleration (expressed as a percent of gravity) in rock with 90 percent probability of not being exceeded in 50 years. The maximum acceleration within the 60 percent contour along the San Andreas and Garlock Faults in California is 80 percent of $g$. (U.S. Geological Survey OpenFile Report 76-416, 1976,) 
Second, the WWSSN system does not adequately record the ultra-long periods normally used in free-oscillation studies. Useful observations of the earth's free oscillations were only identified after considerable processing and then for only a few infrequent great earthquakes.

\section{SUPPORT}

Although the WWSSN provides social benefit and scientific knowledge of a value far greater than its cost, in the past decade it has had a history of perilously inadequate and unstable funding and has followed an uneven and round. about course to its present status.

By 1967, the WWSSN had essentially reached it present configuration. Project VELA Uniform had contributed about $\$ 9$ million and various U.S. institutions more than $\$ 2.7$ million for the purchase of seismographic and photographic equipment and for its installation, general maintenance, and repair. Foreign scientific organizations had contributed perhaps more than $\$ 6.5$ million. The operating budget was less than $\$ 1$ million per year and provided for regular yearly visits to the stations for nonroutine maintenance and calibration. The program was running quite well, but a serious funding problem then began to develop. Project VELA Uniform began to phase out this activity, and Department of Defense (DOD) funds were no longer available for the Network. Adequate support for this program was not made available to NOAA and its predecessor agency ESSA.

After near failure, the network was saved, temporarily at least, through a most welcome but patchy arrangement. Part of the maintenance and calibration activity was cut back, some support of U.S. stations was undertaken by local institutions, limited funds were made available by the agency responsible for the operation and maintenance of the network--the Environmental Science Service Administration (ESSA), and the National Science Foundation (NSF) granted partial, but crucial, support to the foreign segment of the network. Through 1972, NSF continued its partial support of the network at an annual level of $\$ 283,500$, and ESSA supported 31 stations operated by domestic agencies at a comparable level.

In 1973, the responsibility for foreign-station support and data quality control was transferred from the National Oceanic and Atmospheric Administration (NOAA), the successor to ESSA, to the U.S. Geological Survey (USGS), but NOAA retained responsibility for record copying and data 
distribution. The NSF support for the WWSSN was also transferred to the USGS, at the same level, i.e., $\$ 184,100$ for foreign-station support and $\$ 99,400$ to be passed to NOAA for EDS Data Center support. Through fiscal year 1976, the total of awards by NSF in suppoxt of the WWSSN was approximately $\$ 2.5$ million. The NSF commitment to the WWSSN for Data Center support is scheduled to drop to $\$ 60,000$ in fiscal year 1977 and to zero in fiscal year 1978.

In spite of the fact that 75 percent of the WWSSN stations have not been visited in the last five years for calibration and maintenance, the network has, surprisingly, managed to survive and to continue to serve as a primary data source for seismological research. But the inevitable progressive deterioration of record quality to be expected under such conditions is now becoming apparent. The panel considered whether certain stations of limited utility should be closed but agreed that the small annual cost of operation of each such station is warranted by the extended geographical coverage that these stations provide.

Where does support for the WWSSN stand today? The USGS sought direct funding for the WWSSN in its budget request for fiscal year 1976, but this item was deleted from the USGS budget by the Department of the Interior. In fiscal year 1977 budget requests, support for the WWSSN was given a high priority and was part of the "within-target" budget increase requested by the Department of the Interior, but the office of Management and Budget (OMB) deleted the request from the budget. Fortunately, NOAA has provided a long-term solution to part of the problem--funding for record copying and data distribution. After fiscal year 1977, this activity will be supported wholly by NOAA.

In short, current funding commitments are seriously inadequate for proper operation and maintenance of the WWSSN. The Network is in a critical state, and its very survival is still threatened.

A directed effort should be made immediately to improve the WWSSN, which is still very much needed for studies that will provide large practical benefits to the nation and the prospect of substantial scientific advances. The major accomplishments made by scientists using data from the WWSSN indicate that much new knowledge of the earth's systems, processes, and structures awaits the proper tools to discover it. This is frontier science and will yield large dividends from a relatively small investment. Now is the time to make that investment. 
In view of the WWSSN's history, achievements, and potential for new discovery, the Panel recommends that adequate and continuing funding be assured through a stable budget (a) to operate the WWSSN as a basic research facility for U.S. investigators; (b) to provide adequate maintenance and suitable upgrading of the WWSSN; and (c) to provide suitable data organization, storage, retrieval, and distribution facilities. We estimate that funding in the amount of not less than $\$ 860,000$ per year will be needed. 


\section{NEW DEVELOPMENTS \\ AND CAPABILITIES}

Two important new developments over the past decade or so are (1) improved methods for recording earthquakes and (2) improved technical capability in seismic instrumentation.

Great improvement of magnetic-tape recording through the conversion of signals from analog to controlled digital format and the availability of small, compact, and inexpensive recorders could revolutionize the analysis of seismic signals from earthquakes, as it already has in seismic exploration for petroleum using signals from controlled sources. These developments allow high-speedcomputer analysis of spectra, improvement of signal-tonoise ratio, and more complete analysis of seismograms. Combined with the vastly improved dynamic range (several orders of magnitude) and substantial new developments in seismic instrumentation, this great advance in our capability to analyze seismic signals can add greatly to our understanding of the physical properties and structure of the earth and provide new insights into many earth-related problems that are of major significance to society (resources, earthquake-related hazards, and others).

Among the significant advances in instrument technology in recent years, improvement of the quality of long-period data stands out. Long-period seismographs are more sensitive to their operating environment, especially to small changes in temperature and pressure, and resolution is often limited by instrument-related noise. Moreover, until quite recently the structure of earth noise in the longperiod band was not well known. The long-period seismographs used in the WWSSN, for example, cannot resolve earth noise in the 20- to 40-sec band, and long-period signals from many events are not detected although they have energy well above background levels. These problems have largely 
been overcome by advances in technology, and new observing systems have resulted.

\section{HIGH-GAIN LONG-PERIOD SYSTEM}

By careful design and control of the operating environment, scientists have been able to increase the operating sensitivity of long-period seismographs by more than an order of magnitude for periods above about $20 \mathrm{sec}$ as compared with the WWSSN system. This work resulted in the installation of the high-gain long-period (HGLP) seismograph system, which includes digital recording to increase the dynamic range. Eleven HGLP systems have been installed as part of a study of very long-period seismic waves sponsored by the Defense Advanced Research Projects Agency (DARPA). This system lowers surface-wave detection thresholds substantially.

\section{SEISMIC RESEARCH OBSERVATORIES}

Problems with long-period-data recording were not all resolved by the HGLP system, however. Wind-generated seismic noise often masks small earthquakes recorded on the HGLP system, particularly the horizontal components because of their sensitivity to ground tilt. However, windgenerated earth motion is attenuated rapidly with depth, and thus attention soon focused on the development of a borehole seismometer that could be used for long-period sensing at depths in the hole where wind-generated noise is reduced (see Figure 8 ). The sensors had to be small compared with conventional seismometers, with low internal system noise yet sensitive enough to resolve long-period earth displacements measured in angstroms. Miniaturization was achieved by using three orthogonally oriented shortperiod seismometers as the sensing elements, and instrument noise was reduced to acceptable levels by employing the latest electronics technology and evacuating the air from the sensor modules. The signal output from each sensor is broadband and is proportional to earth acceleration from 0.02 to $1 \mathrm{~Hz}$. The broadband data are filtered in a wellhead terminal to produce long-period and short-period outputs, which are recorded separately. Operated in a borehole at a depth of $100 \mathrm{~m}$, this new seismometer is unaffected by wind noise, even during periods in which the noise obliterates data from conventional seismometers operated near the surface. 


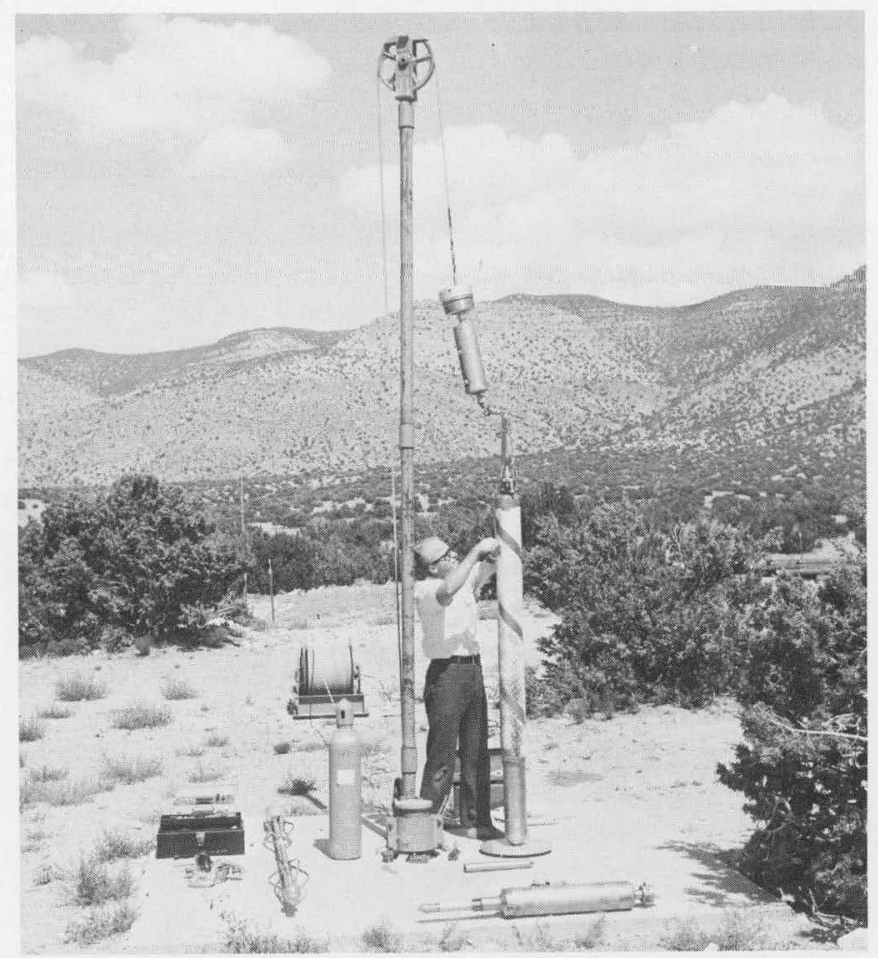

FIGURE 8 SRO borehole seismometer being prepared for installation. (Photo U.S. Geological Survey, Jon Peterson.)

Improvement of long-period sensing using the advanced borehold seismometer described above was one goal in the development of the network of Seismic Research Observatories (SRO). Another equally important objective was to achieve a capability to accommodate a large range of signal amplitudes. Most conventional seismographs, like the WWSSN instruments, record photographically on drum recorders to produce the typical 24-hour seismogram. The recording range is quite limited, about $44 \mathrm{~dB}$, or a little over two orders of magnitude $(\times 100)$. A digital recording system of the type used in the SRO project provides an excellent alternative, with $66 \mathrm{~dB}$ of resolution plus $60 \mathrm{~dB}$ of automatic gain control for a total of $126 \mathrm{~dB}$ of recording range, over 6 orders of magnitude $(\times 1,000,000)$. Three long-period data channels and the vertical-component short-period data channel are recorded on visual recorders to produce conventional seismograms. The same data are digitally recorded, with 


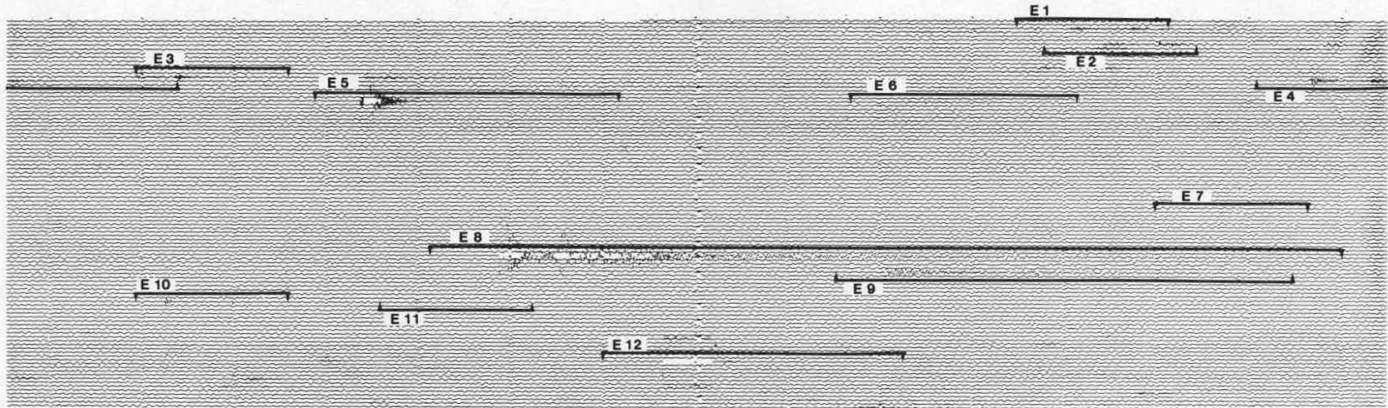

E1-REGIONAL

E2-REGIONAL

E3-REGIONAL

E4-REGIONAL

$$
\text { GIONAL }
$$

\section{E5. QUAARY BLAST}

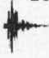

E6-TELESEISM

wasin....

E7. $M_{b} 4.990^{\circ}$

\section{E8. $M_{b} 5.8 \quad 83^{\circ}$}

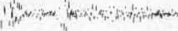

ancherp.

\section{E9-TELESEISM}

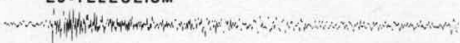

\section{E $10-M_{b} 5.4 \quad 92^{\circ}$}

E11- $M_{b} 4.982^{\circ}$

E12-CALIBRATION

mane

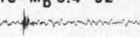

wivind

FIGURE 9 Example of short-period event editing. Upper part of the figure shows a 24-hour seismogram with 12 recorded events or earthquakes indicated by $b$ : lines. Only the events were digitally recorded on 1 and :s of them are shown in the lower part of the figure. etic tape, Geological Survey, Jon Peterson.) 
the long-period data sampled once each second and the short-period data 20 times each second. The station processor is a 16-bit minicomputer with 8000-core memory and peripheral controllers. In addition to controlling the recording operations, the station processor edits the short-period data so that only a short segment of data prior to each event, and the event itself, are recorded on tape (see Figure 9). The station operator communicates with the processor and controls the system through a teletypewriter. The system appears to be reliable. A prototype SRO has been operating for 18 months at Albuquerque with very few failures of component parts.

Sites for 13 SRO stations were selected jointly by DARPA and the U.S. Geological Survey on the basis of recommendations from the Committee on Seismology of the National Research Council. Most will be operated in conjunction with WWSSN stations. Specific considerations were seismic noise levels as determined from existing data, geological setting, and the interest of prospective host organizations. The general geographical siting of the SRO stations was influenced by the location of existing HGLP stations.

\section{ABBREVIATED SEISMIC RESEARCH OBSERVATORIES}

In a project closely associated with the SRO's, five of the HGLP seismograph stations will be furnished with vertical-component short-period seismometers and abbreviated versions of the SRO recording system. These modified HGLP stations (designated ASRO) will have functions, software, and a digital data format identical to those of the SRO stations; the principal difference is that the ASRO stations will continue to use conventional surface longperiod seismometers.

Figure 10 shows the locations of the HGLP, SRO, ASRO, and IDA (see p. 34) stations. Figure 11 shows the operations characteristics of the WWSSN, HGLP, and SRO systems.

\section{ARRAYS}

Since the early 1960's, large arrays of seismometers have been installed by the United States as research systems in Montana, Alaska, Norway, Korea, and Iran. Great Britain and other countries are operating medium-sized arrays. DARPA is the U.S. governmental agency that has primary responsibility for the U.S. program of installation and 


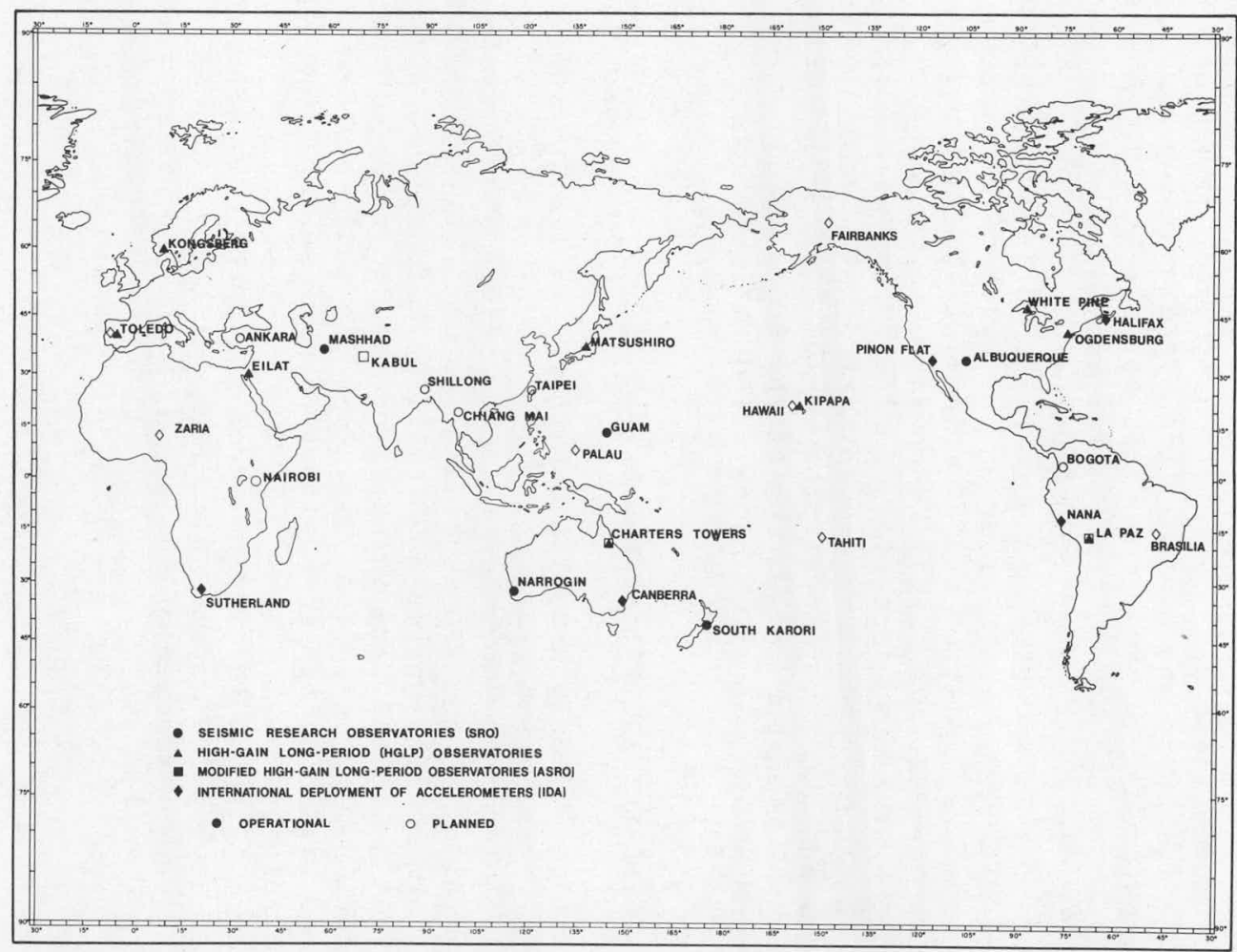

FIGURE 10 Existing and planned locations for the HGLP, SRO, and IDA stations. (Courtesy of U.S. Geological Survey.) 


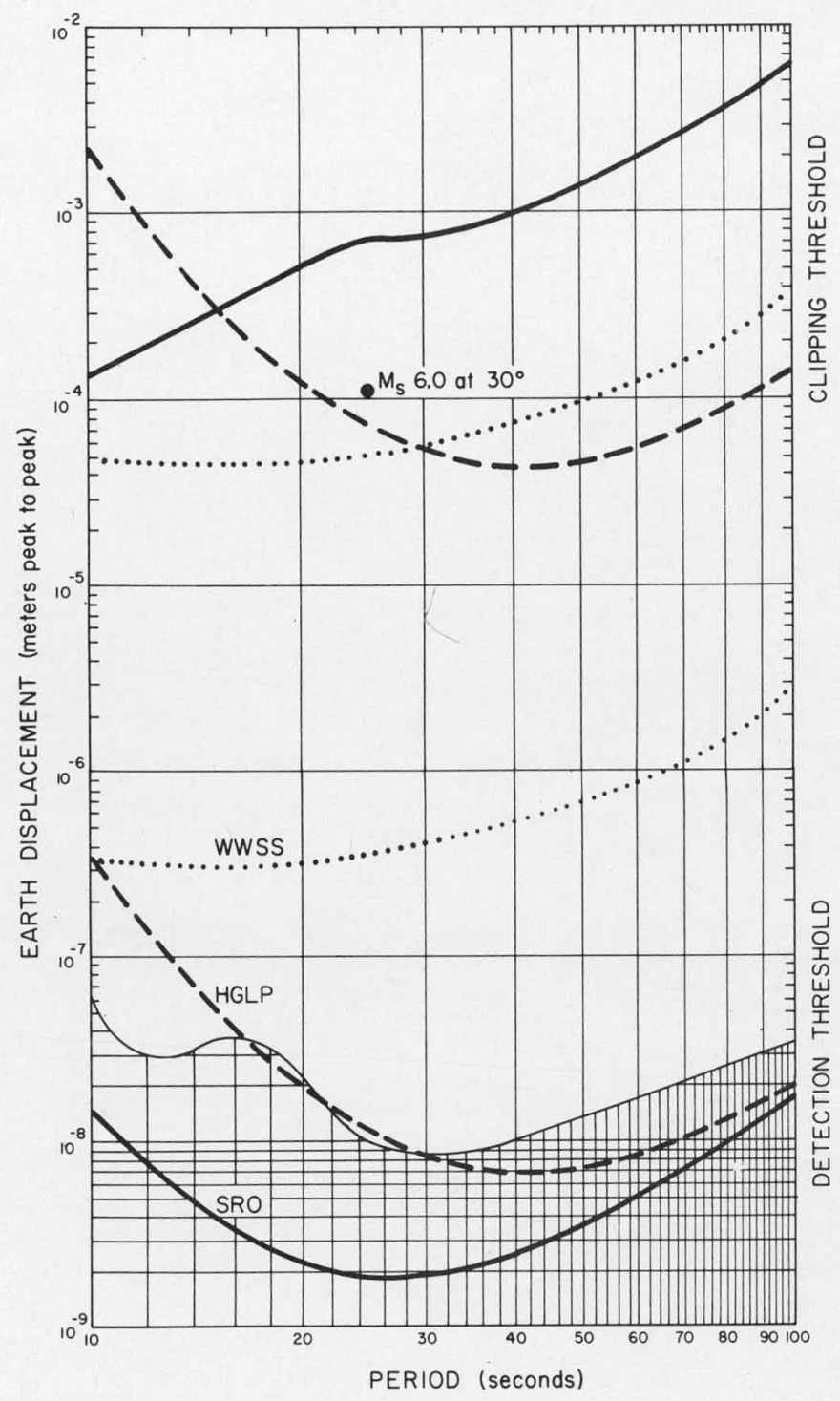

FIGURE 11 Comparison of the recording ranges of the WWSSN, HGLP, and SRO systems for longperiod waves. (From J. Peterson and N. Orsini, E®S, Trans. Am. Geophys. Union 57, 548-556, 1976, copyrighted by American Geophysical Union.) 
DISTRIBUTION OF 2 I

SUB-ARRAY CLUSTER WITHIN LASA \&

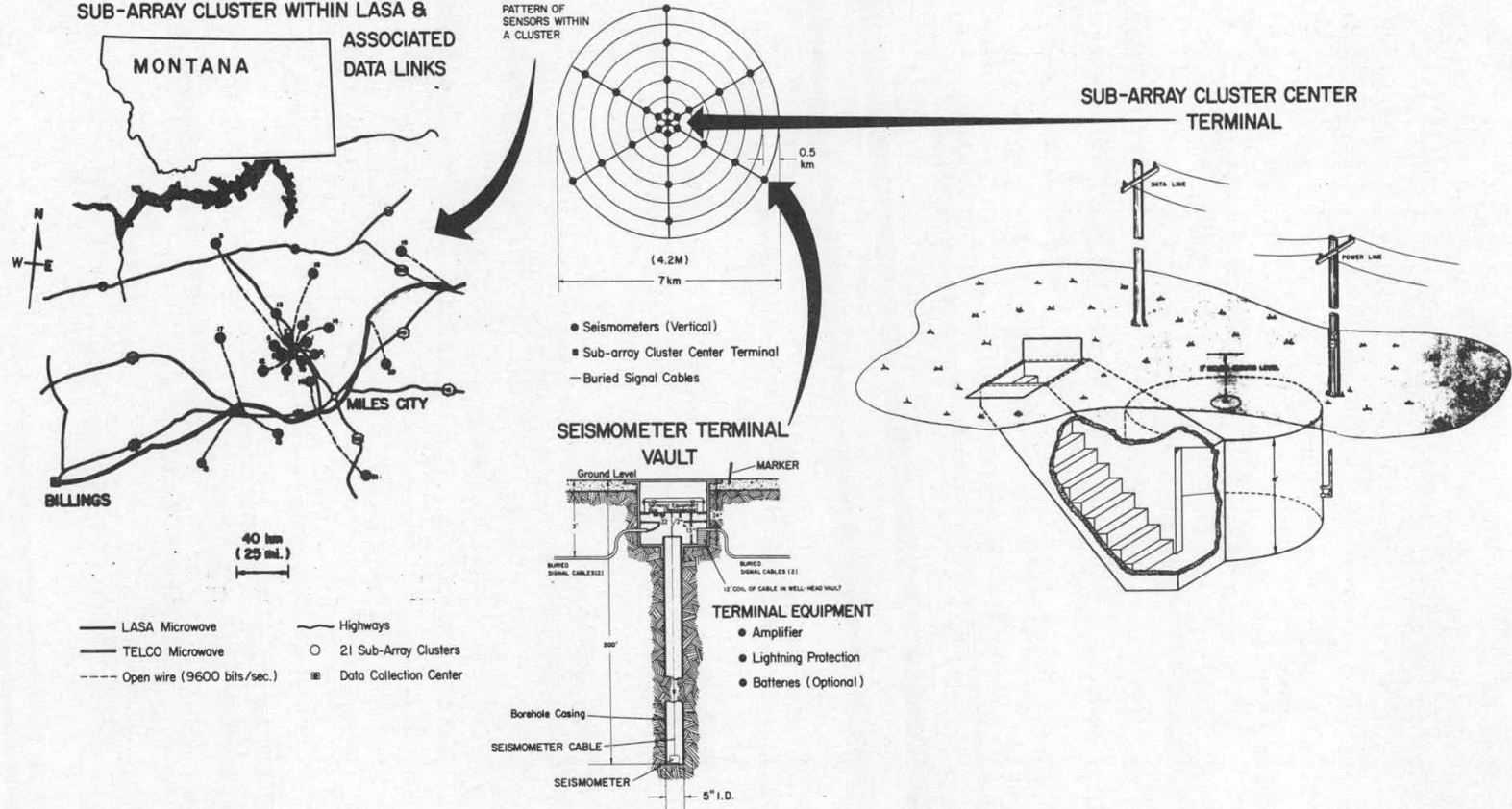

FIGURE 12 Schematic diagram of Large Aperture Seismic Array in eastern Montana. Data from approximately 300 seismometers are recorded digitally. An array of seismometers allows for the detection of small seismic signals and detailed studies of seismic propagation phenomena. (Provided by DARPA.) 
operation of the arrays in conjunction with the host country. The aperture of a given array may be $50-100 \mathrm{~km}$, and the number of seismometers in the array may be 100 or more (see Figure 12). The data from these units have been useful in signal enhancement, phase identification, and earth-structure studies in general. Considerations in using array data must involve the large amount of data available for a given event and the ensuing processing time and costs.

\section{DATA STORAGE AND DISTRIBUTION}

The principal purpose of the new stations (HGLP, SRO, and ASRO) and of the WWSSN is to provide data for research, and the success with which this purpose is met depends on accessibility of their data to researchers. For years, conventional seismograms have been sent to the National Oceanic and Atmospheric Administration's Environmental Data Service (EDS) or to its predecessors for microfilming and distribution of copies to subscribers. This service will continue, but for the new digital stations, the reproduction of seismograms or film chips from the digital tapes is being considered as an alternative to the collection and processing of station seismograms. The reproductions are superior to the conventional seismograms in several respects; for example, they have greater dynamic range and can be plotted at any magnification. A complementary data-management system is being established by DARPA to process, store, and disseminate data collected from the digital-recording network and from the seismic arrays in Montana, Alaska, Norway, Korea, and Iran. The short-period array data will be analyzed by automated event-detection and event-association processors to produce a daily summary of events and their associated parameters. The event summaries, associated waveforms, and raw array data will be placed in a mass data-storage device to be augmented later by SRO network data as tapes are received from the stations. Access to this data bank will be provided through the DARPA-sponsored Seismic Data Analysis Center (SDAC) in Alexandria, Virginia, and, as is the practice with WWSSN data, the data will be made available to the international seismological community. 


\section{INTERNATIONAL DEPLOYMENT OF ACCELEROMETERS}

Another development of the past decade has been the improvement of instruments for measuring very-long-period (VLP) ground motions--those with periods of more than $100 \mathrm{sec}$. The LaCoste-Romberg gravimeter, with electrostatic feedback, has demonstrated long-term stability unattainable with systems utilizing conventional mechanical suspensions. High-quality seismic data for periods greater than $40 \mathrm{sec}$ are currently being recorded digitally on cassette tapes from a small global network of stations equipped with the modified LaCoste instrument (see Figure 13). This is the
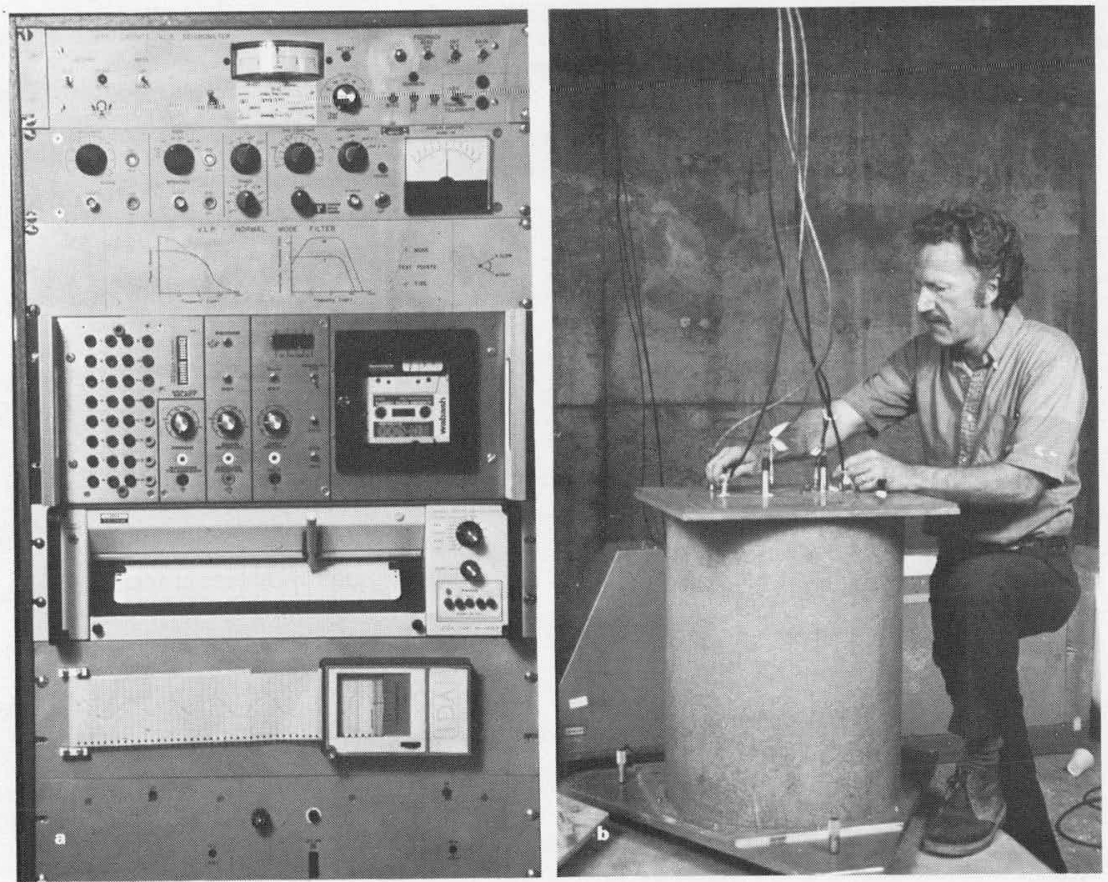

FIGURE 13 (a) The IDA system electronics rack. Included from the top are the feedback and bias control chassis, the lock-in amplifier, the tide and mode filters, the cassette recorder, two monitor strip chart recorders, and the power supply with battery charger. (b) Donald Miller attends the La Coste-Romberg gravimeter in its constanttemperature container. The micrometers on the baseplate are used for initial leveling and subsequent tilt calibration. (Photos courtesy Jonathan Berger.) 

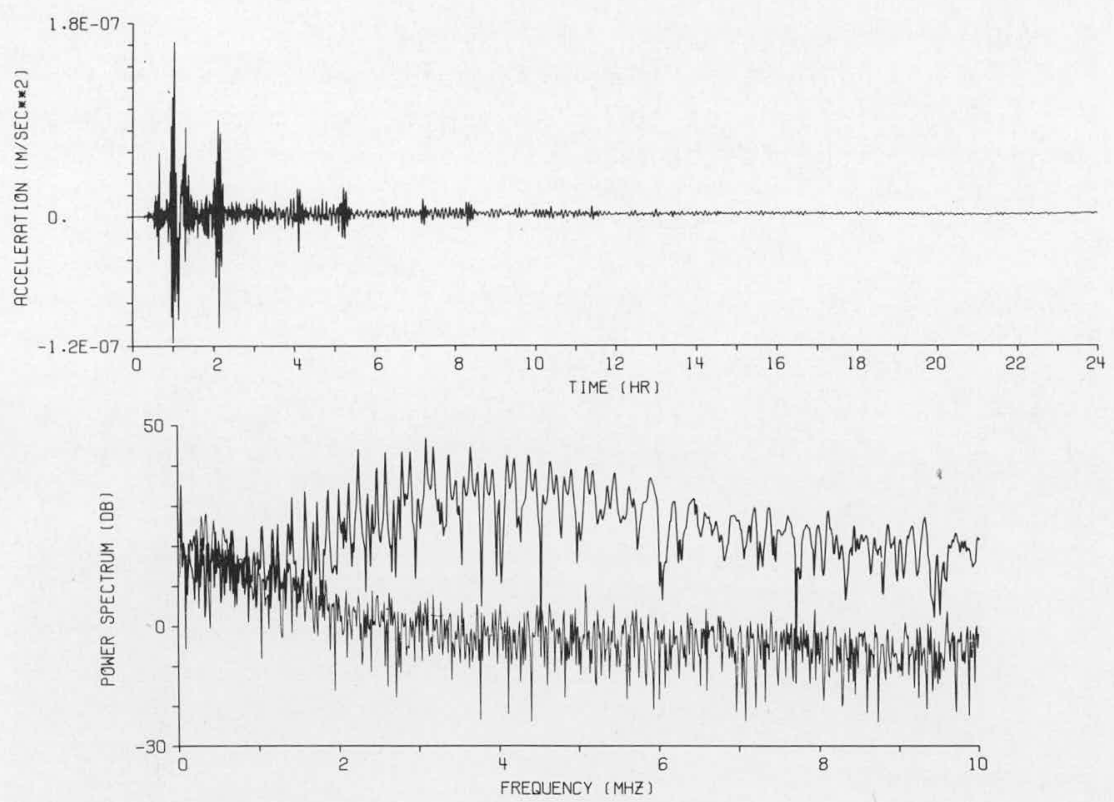

FIGURE 14 Fourier power spectra (in $\mathrm{dB}$ ) of the IDA records at Sutherland of the Guatemalan earthquake, February 4, 1976. The lower spectrum represents the earth's background noise plus instrument noise for the 24-hour period before the earthquake. The upper spectrum represents the earth's normal mode activity for the first 24-hour period after the earthquake. For frequencies above $2 \mathrm{mHz}$ the $\mathrm{S} / \mathrm{N}$ is about $35 \mathrm{~dB}$. The $\mathrm{O}-\mathrm{dB}$ point corresponds to a power level of $5 \times 10^{-16} \mathrm{~m}^{2} \mathrm{sec}^{-3}$. (Courtesy Ray Buland.)

International Deployment of Accelerometer (IDA) project, whose station locations are shown in Figure 10. In early 1976, there were 5 of these stations, and plans call for a total of about 15 eventually. Digital recording, in conjunction with active filters, provides a dynamic range of over $100 \mathrm{~dB}$ for periods between 2 and $60 \mathrm{~min}$. The cassette tapes, after processing by minicomputer, produce VLP data that can be used for earth-tide studies and for investigations of earth structure and earthquake mechanisms using free oscillations and surface waves (see Figure 14).

\section{POTENTIAL FOR VERY-LONG-PERIOD MEASUREMENTS}

The nominal long-period band for the SRO instruments is 10-100 sec. At longer periods, the active filters have a 
decrement of $20 \mathrm{~dB} /$ decade. Yet, preliminary results for the Solomon Islands earthquakes of July 20, 1976, as recorded at Albuquerque, show that the spectrum of the vertical SRO instrument contains free-oscillation peaks at very long period (for example, the mode ${ }_{0} \mathrm{~S}_{13}$ with a period of $473 \mathrm{sec}$ is present with a signal-to-noise ratio of about $10 \mathrm{~dB})$. Therefore, it may be possible to use SRO instruments to study very-long-period phenomena, especially source mechanisms. However, to realize this possibility requires that broadband, very-long-period ( $T>100 \mathrm{sec}$ ) active filters be developed, evaluated, and calibrated for these instruments. It is also worthwhile to investigate the long-period characteristics of the ASRO and HGLP systems. Together, the 15 IDA stations along with the verylong-period channels of the other instruments can provide very good global coverage at very low frequencies. Because of the potentially important relationship between low-frequency spectra to source mechanisms and precursory phenomena, the evaluation of the very-low-frequency characteristics of the instruments of the combined networks should have a high priority.

\section{ADMINISTRATION AND SUPPORT OF NETWORKS}

All of these networks (HGLP, SRO, ASRO, and IDA) are composed of research stations that make their data available to all researchers. The results thus far have been rewarding for special studies, and much additional basic information about the earth can still be derived from the observations of these stations. Yet these stations, which have cost perhaps $\$ 5$ million or more to install, may be lost to us before the end of this decade, after only a few short years of operation, because of termination of support--even though operational and maintenance costs are relatively small, averaging about $\$ 17,000$ annually per station. Considering the large investment in installation and the substantial new knowledge that could be expected from continued operation of these stations, it is clearly within the national interest to provide long-term support for them. The Panel, therefore, submits the following recommendations:

A. Sufficient support should be provided to the U.S. Geological Survey under a stable budgetary arrangement to assure continuing operation, maintenance, and improvement 
of the new networks (HGLP, SRO, ASRO, and IDA), with reviews of results and performance at 5-year intervals.

B. A plan should be formulated for an orderly transfer of responsibility to the U.S. Geological Survey for funding the long-term continued operation and maintenance of seismic networks and arrays, including global networks.

C. A plan should be formulated for the National Oceanic and Atmospheric Administration to expand funding and increase facilities for the long-term storage and distribution of observations from seismic networks and arrays.

D. The responsibility for formulating the plans discussed above should be vested in an interagency initiative definitely including the Defense Advanced Research Projects Agency, the U.S. Geological Survey, the National Oceanic and Atmospheric Administration, and the National Science Foundation.

THE NEED FOR PORTABLE INSTRUMENTS

In addition to the networks of permanent stations, the availability of a system of portable broadband, digital instruments to be used on a worldwide basis would be of great importance to studies of aftershock sequences, mapping of upper-mantle discontinuities and regional structure, studying waveforms of phases diffracted or refracted on or near the core-mantle boundary, regional surface-wave dispersion, identification of geothermal sources, and many other similar studies. The instruments could be located with several of these purposes in mind and the data made available to the seismology community. The transmission of data from such a portable system by means of satellites may be economically feasible and would offer advantages in terms of real-time monitoring of station performance.

The Panel recommends that portable broadband, digital instruments be obtained for a variety of fundamental investigations for which high-density instrumental coverage is necessary for a limited time.

\section{SPACE-RELATED STUDIES}

A set of geophysical stations is being established by the National Aeronautics and Space Administration (NASA) in a 
program of using space-related techniques to study crustal strain and lithospheric-plate motion. Lunar laser-ranging stations are operating at McDonald observatory at Fort David, Texas, and Haleakala Observatory on Maui Island, Hawaii. Geophysical instrumentation consisting of longperiod and short-period seismometers, tiltmeters, strain meters, and gravimeters are being installed at these stations. The data from these instruments will be recorded digitally and will be made available to interested scientists. Similar instruments will be operated at sites to be occupied beginning in the late 1970's by a transportable lunar laser-ranging facility now being constructed. These sites will probably include Goddard Space Flight Center in Maryland, Haystack Observatory in Westford, Massachusetts, and a location in the Pacific Northwest. Similar lunar laser-ranging stations are also being constructed in Australia, Japan, France, and the Soviet Union.

The Panel urges that the data derived from this effort be supplied to interested investigators through NOAA's Environmental Data Service.

\section{OCEAN-BOTTOM SEISMOGRAPHS}

Ocean-bottom seismographs (OBS) can be used both to augment the global network and to provide more precise information about the regional structure of the oceanic crust and upper mantle. Together, the oceans represent a unique tectonic province that has never been directly sampled with seismic methods, except for the most shallow structures. At present, recordings of surface and body waves generated by earthquakes in the oceans must be made on continental platforms or on oceanic islands that are different geophysically from typical oceanic regions.

Major differences between continental and oceanic structure have been known for some time, and the hypothesis has been advanced that some of the more extended differences persist to great depths. A detailed understanding of uppermantle structure beneath the oceans is required if the composition and dynamics of the entire mantle are to be fully understood. To obtain this information certainly requires that the global network include ocean-bottom seismographs that can remain in operation for a long time.

The technology of self-contained, free-drop, OBS capsules has advanced to the state that deployment times of as long as a year can now reasonably be considered (see 
Figure 15). Stations of a more permanent nature, utilizing tethered buoys, acoustic data links, or oceanic telephone and telegraph cables appear to be feasible. These promising developments now make it possible to consider longterm experiments on the ocean bottom with the assurance that enough earthquakes will be recorded to provide good digital and analog data bases. Ocean-bottom seismograph sensors now in use, or soon to exist, are sensitive to very long, including tidal, periods as well as to shortperiod ground motions. That is, the modern vertical seismograph is also a sensitive gravimeter, and the horizontal seismograph is a sensitive tiltmeter. Thus, these instruments will enable scientists to extend greatly their studies of gravity and of load and tilt tides, as well as other infraseismic phenomena. Global tidal observations would be useful in conjunction with computer solutions of the Laplace tidal equations, to mention but one interrelationship of geodesy, oceanography, and seismology.

The existence of such a geographically comprehensive data base would create new areas of opportunity and expand existing ones as seismologists continue to improve their knowledge and understanding of the earth and earthquakes.

The Panel recommends a comprehensive research effort to determine the feasibility of an extensive, long-term program in ocean-bottom seismology. Such a program might include portable arrays of several broadband OBS instruments and a few permanent installations.

\section{CALIBRATION}

To use amplitude information effectively in studies of structure and source mechanisms requires that the instruments be well calibrated. The nonlinear as well as the linear response functions of the instruments must be known. All instruments are nonlinear for sufficiently large signals, and both the SRO and IDA instruments exhibit obvious nonlinearities in their responses to Rayleigh-wave packets $(R)$ for large earthquakes $\left(M_{S}>7\right)$. This nonlinearity causes the frequency spectrum of the input (the sensed ground motion) to be convoluted with itself and weighted with the instrumental nonlinear reponse function. The result is a distorted output spectrum that can lead to erroneous interpretations. Therefore, a general procedure, such as cross-correlation, should be developed, evaluated, and applied to the calibration of 
FIGURE 15 (a) View of assembled digital ocean-bottom seismograph. Tripod at bottom couples to the sea floor and is left on the bottom after release. The 22-inch inside-diameter sphere is positively buoyant. An acoustic link, whose transducer is mounted at the top, allows accurate location of the system on the sea floor and permits capsule diagnostics and release commands to be exchanged with the mother ship. The flashing light and radio beacon are used to locate the capsule on the surface. (b) Interior components of digital ocean-bottom seismograph. One-second "Ranger" seismometer is at bottom with electronics assembly suspended by shock mounts above. 12-bit data are recorded in serial format with commercial recorder on top. The system is entirely digital and incorporates CMOS, low-power technology throughout. A three-component, CMOS microprocessor, long-period capsule is currently under construction. (For details see W. A. Prothero, 1976. A free fall seismic capsule for seismicity and refraction work, Offshore Technology Conference Paper No. 2440. Photos courtesy of Marine Seismology Group, Scripps Institution of Oceanography.)

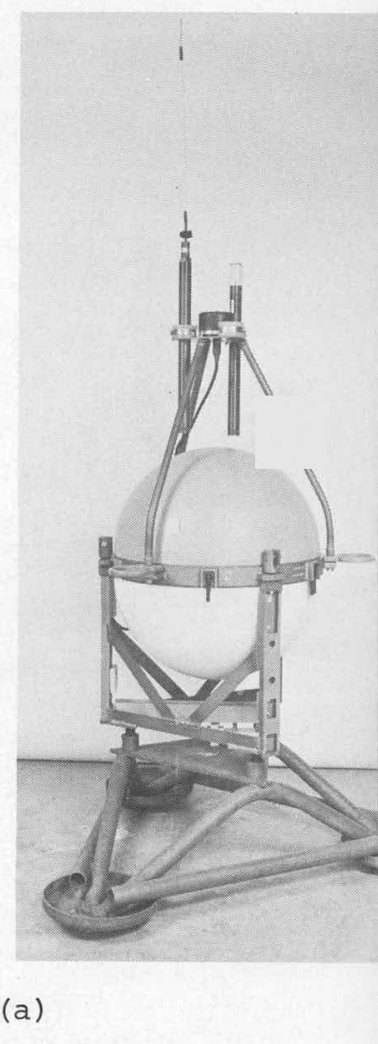

SRO, IDA, and other instruments. The broadband linear response function, quadratic response function, and, if necessary, cubic response function should be determined to good accuracy. In this way, the user could decide which signals to accept and whether to apply a relinearizing postprocessing procedure.

Calibration of the instruments is obviously important and should be given high priority if users are to receive the benefits of broadband digital data. Weakly nonlinear signals can be deceptively attractive but seriously misleading. They cannot be identified unless the instruments are well calibrated. Certainly, more consideration will have to be given to what is needed before regular site visits for calibration can be made. 
The Panel recommends that some instruments at these stations be run at very low gain to ensure that all data possible are obtained. In addition, if near-field effects predicted from far-field observations are to be verified, it is absolutely essential to have strong-motion instruments at WWSSN stations located within or close to seismically active areas. 


\section{IMPROVED WORLDWIDE}

The preceding discussion has reviewed the characteristics, findings, and future potential of the WWSSN and other networks. It has become clear that an integrated global system that combines and takes advantage of the special individual capabilities of all of these networks could produce results far beyond those that can be expected from them separately. Such an integrated system, with digital recording capability and augmented by ocean-bottom seismographs and by portable instruments for short-term field studies of particular earthquakes, is essential for anticipated studies of the intexnal structure and dynamics of the earth, of regional structure, and of earthquake source mechanisms. (See Appendix A.)

\section{DESCRIPTION}

Ideally, the improved worldwide network would have broadband instruments sited in an optimal geographic configuration. The locations of the $25 \mathrm{HGLP}$, SRO, and ASRO stations currently supported by DARPA are shown in Figure 10. These instruments provide three components of the long-period band and, except for the HGLP, the vertical component in the short-period band. At present, the band of 10-100 sec is recorded continuously, and an event detector is used in recording the short-pexiod band. Different active filters could be used to extend the long-period band. For large events, $M_{S}>7$, the signal-to-noise ratio (S/N) for SRO stations appears to be favorable for periods as long as $500 \mathrm{sec}$. It would also be desirable to provide an additional broad passband, possibly event triggered, to include recording of intermediate-period (5-10 sec) data.

The IDA program, sponsored by NSF and pri.vate funds, involves the deployment of 15 very-long-period LaCoste- 
Romberg gravimeters. The band extending from $40 \mathrm{sec}$ to tidal periods (approximately 12 hours) is continuously recorded digitally on cassettes. These stations (see Figure 10) should be included in the improved global network, and the data should be collected by EDS.

It is desirable to select about 50 current WWSSN stations for upgrading, the selection to be made primarily on the basis of geographical location, and to provide digital-recording facilities for at least the vertical components. The long-period band, yet to be defined exactly, would be recorded continuously, and the short-perind band could be supplied with an event detector, in the sam manner as for the SRO and ASRO instruments. It would alsu be desirable to record some data from intermediate periods. In areas where key geographical coverage is lacking, it may be necessary to upgrade reliable non-WWSSN stations to WWSSN status with digital-recording capability.

All together, we have identified about 90 installations for the basic integrated network, thus permitting the system to provide sufficient data for the study of source mechanisms, dispersion characteristics of fundamental- and higher-mode surface waves, amplitudes of long-period body waves, and frequencies and line widths of the earth's free oscillations. Regional and global earth structures could be better delineated, and the temporal and spatial characteristics of sources could be better defined. It should be emphasized that this digital-data recording system is not intended to replace the current WWSSN recording capability but to complement it. Existing visible or analog recording facilities of the WWSSN are essential to traveltime studies, in particular, and should be continued. On remote islands, for example, these may be the only practical means of recording, and many foreign countries do not have the facilities to make full use of a digital data base. Moreover, some researchers may be limited to the use of analog data by lack of training in digital processing techniques, by a lack of data-processing facilities, or by a lack of research funds for computing purposes. It is therefore essential that the United states continue to acquire analog data from as many stations as possible and to ensure that geographical coverage is as complete as possible.

To further augment the improved WWSSN, the data from the NASA geophysical stations (described above) should be collected by EDS (NOAA) for the use of investigators.

A great deal of valuable data are also available from 
seismic arrays such as the Large Aperture Seismic Array (LASA) and the Norwegian Seismic Array (NORSAR). All the array data could easily overwhelm the envisaged digitaldata collection and distribution facilities. One alternative is to include only selected data from arrays, such as subarray beams, array beams, or subarray center elements; another alternative is to maintain a separate data center for the array data.

Including a network of strainmeters would also be valuable, especially for the study of ultra-long-period phenomena. Benioff (quartz rod/tube) meters (now installed in stations at Ogdensburg, Boulder, Isabella, and Ñaña), laser strainmeters (in Albuquerque, Boulder, Piñon Flat, and California) and Sacks-Evertson volumetric meters, already in operation in North America, South Africa, and Japan, could form the basis for a strainmeter network. Wire strainmeters (Great Britain and Iran) might also be considered. By recording the output of these meters digitally and by making the data available in a simple format at a central site such as EDS, a working network of strainmeters could quickly be established.

To augment the fixed stations of the global network to provide a sufficient number of the broadband observations for regional studies, we envisage a system of portable broadband digital instruments that could be used for a variety of purposes that require high-density instrumental coverage for a limited time. These instruments could be quickly emplaced in the aftershock regions of large earthquakes to provide needed information for studies of earthquake source mechanisms, regional upper-mantle properties, diffracted waveforms, geothermal sources, and regional surface-wave dispersion.

Stations on oceanic islands help to improve the geographical coverage; seismographic stations operating on the ocean bottoms must also be given serious consideration and support. Many of the technical problems associated with the deployment and long-term, high-gain recording of the OBS have been solved. However, some research and development still remains to be done in order to produce an instrument package for long-term emplacement on the bottom together with a suitable method for sampling the data. A field program with three-component broadband sensors extending to very long seismic-wave periods could be undertaken probably by the end of 1978. About five institutions in the United states are capable of carrying out this program, either individually or jointly. 
By properly coordinating the recordings, archiving, and distribution of data from the improved WWSSN, the potential power of this network can be made available to all interested users. And we can anticipate that data-exchange agreements with other countries will further augment its effectiveness. It is especially desirable to have better coverage of the large continental areas from which we do not now receive data. Such areas include West Africa and the People's Republic of China.

\section{SUMMARY}

There now exists the basis for a global system having digital recording capability for anticipated studies of global structure, regional structure, and source mechanisms. It would consist of 25 installations from the programs of HGLP, SRO, and ASRO stations; 15 very-long-period gravimeters deployed under the IDA program; and about 50 stations of the WWSSN improved with digital recording. Ideally, this global earthquake observation system would have broadband instruments sited in an optimal geographical configuration. The addition of a number of portable broadband digital instruments would be of great importance to many studies, including aftexshock sequences, areas of geothermal interest, and source mechanisms. Selected data from seismic arrays could be added. Including digitally recording strainmeters would also be valuable. The NASA program for installation of geophysical instruments globally could also contribute elements to the integrated global system. The development and deployment of oceanbottom seismographs could also enhance the effectiveness of the proposed global network. All together, a broadband integrated digital system using the data of over 100 installations is envisaged. In addition, data-exchange agreements with other countries can provide better coverage of large continental areas from which we do not now receive data.

To assure that the global network system functions at its maximum capability, the organization, collection, storage, and dissemination of digital data must be upgraded accordingly, and special regional research centers should be established to support users of digital data. (This is discussed in detail in chapter 8 and referred to in recommendations $\mathrm{B}$ and $\mathrm{C}$, below.) 
To achieve a new level of seismic research capability far beyond that possible with present network facilities, the Panel recommends the following:

A. Stable budgetary support for the improved WWSSN should be provided to the U.S. Geological Survey so that this system can provide a modern data base for the seismologicai community. The improved WWSSN would consist of the following components: HGLP, SRO, ASRO, IDA, selected WWSSN stations, OBS, and other appropriate instruments and facilities.

B. A system for collecting, organizing, archiving, and distributing digital data to the seismological community should be established. The USGS Albuquerque Seismological Laboratory is recommended as the facility to carry out basic quality control of incoming digital seismic data and merging onto magnetic tapes, and the NOAA/EDS is recommended as the facility for archiving and distributing the data on magnetic tapes.

c. Regional research centers should be established that would provide a library of digital seismic data, access to modern computer facilities, required software for processing the data, and a support staff. 


\section{INTERNATIONAL ASPECTS}

Seismologists were aware very early of the need for data collection on a global scale. Therefore, in addition to organizing networks of stations, they developed various means for assembling and communicating data in various forms. The International Seismological Centre (ISC) in Great Britain, the Bureau Centrale Internationale Seismologique (BCIS) in France, and the U.S. Geological survey's National Earthquake Information Service (NEIS) are examples of centers that were created to systematically collect, process, and distribute earthquake data and hypocenter locations. This careful, comprehensive analysis of worldwide earthquake data has been and continues to be a powerful influence toward the excellence of past and present seismological research, and continued support for the work of these centers is needed.

A glance at the map of station distribution (Figures 4 and 10) shows that the combined WWSSN and digital network would provide good, but not complete, worldwide coverage of stations. However, some large land areas in Canada and the Soviet Union, for example, are covered by networks of those countries, and while the networks use instruments different from the U.S.-supported networks, they are internally standardized and caljbrated. Data from the Canadian network is often used to complement those of the WWSSN.

Many seismological problems important to the United States require data on a global scale, and a strong program of data exchange with other countries is a necessity. This was an important consideration in the establishment of the WWSSN, and one of the greatest contributions of that network has been the enormous reduction in the time required for an investigator to obtain a set of seismograms for an event he has chosen to study. This service needs to be expanded through formal arrangements among national 
networks, so that the seismograms of large numbers of earthquakes recorded at observatories distributed over much of the earth's surface can quickly be made available to scientists in all participating countries: One method of distributing data internationally from a relatively large network is that now used by the Canadians. Records from the Canadian national network are microfilmed by the Dominion observatory, and a master microfilm copy is made available to the Environmental Data Service (EDS) in the United states. The EDS then makes copies of this microfilm on request, charging only the cost of copying. The U.S. Government pays no additional costs, and the cost of exchanging original seismograms is avoided.

International cooperation in seismology is also fostered through the International Association of Seismology and Physics of the Earth's Interior (IASPEI) and its parent organization the International Union of Geodesy and Geophysics (IUGG). Through the International Council of Scientific Unions (ICSU), of which the IUGG is a member, the World Data Centers (WDC's) were created during the International Geophysical Year (IGY). WDC-A is in the United States, WDC-B in the Soviet Union, and WDC-C in western Europe and Japan. Since 1973, the WDC's have been acquiring and distributing copies of seismograms of important earthquakes. The IUGG also joins with other major scientific unions for the development of international programs of mutual interest. A good example of such a program, of interest to seismologists, is the International Geodynamics Project (IGP), which is under the guidance of the International Geodynamics Commission (IGC). The Panel on Seismograph Networks has invited comment from IASPEI and its correspondents about the value of the WWSSN to the international seismological community and about ways in which the new digital-data-acquisition systems may benefit it. (See Appendix B.) The responses received overwhelmingly favor continued operation and improvement of the WWSSN, deployment of digital-recording systems, and development of a system for ready availability of digital data.

It is worth emphasizing that the contribution to the WWSSN by the countries in which the foreign stations are located has been substantial, and, again, that U.S. support of foreign stations is fully justified in terms of the needs of American science. The accompanying benefit to international scientific progress is a highly desirable by-product. 
Program of international exchange of seismological data have been essential to the success of seismological research from its beginning.

The Panel recommends that such international cooperation and exchange be continued and expanded and that particulax emphasis be given to the exchange of digital data to augment the proposed integrated global network. 
8 DATA HANDLING, PROCESSING,

The Panel expects that during the next five years digital seismic data will become available from a variety of sources, previously discussed in detail. We urge that data from Seismic Research Observatories (SRO's), the HighGain Long-Period (HGLP) network, stations of International Deployment of Accelerometers (IDA) program, selected data from seismic arrays, and geophysical observatories installed by NASA be considered together as a single comprehensive data base--but again, not to the exclusion of analog data.

In addition, a number of digital arrays and single stations are operated around the world by other countries, including Canada, Mexico, France, Germany, and Sweden; arrays are operated by the United Kingdom in Australia, India, and Brazil. Data from certain of these sources, if obtainable on an exchange basis, would complement the global data of U.S. digital stations. Efforts should be made to ascertain the availability of these data and to examine their utility to the U.S. data base.

There is an immediate need to establish a centralized distribution facility for a strainmeter records, but, because of the great variety of instrumentation currently employed, this may be a difficult task. However, we encourage examination of available strainmeter data sources and hope that in the near future at least some of this type of data may be included in the U.S. data collection..

Collection, data handling and processing, organization, and archiving of analog seismic data are carried out by the Environmental Data Service (EDS) of the National Oceanic and Atmospheric Administration (NOAA) at its Data Center in Boulder, Colorado. Seismograms are mailed to EDS, mostly via the USGS in Golden, Colorado, to be microfilmed and archived. The Panel encourages the work of EDS and urges 
its continued funding at a level that will prevent backlogging of seismograms awaiting reproduction and the resulting delays in data orders.

The potential volume of data from digital seismic stations is great, and EDS should assume responsibility for the storage and distribution of these data. It makes a great deal of sense for the same organization to handle both analog and digital data, and EDS is highly qualified for this task.

Some problems in connection with the processing of digital data require examination. These include data review, quality control, and reformatting. Quality control is necessary to correct errors in header information stored on the magnetic tapes and to remove other possible sources of error caused by poor tape quality of other problems. Reformatting is necessary because most individual stations record for up to two weeks on a single reel of tape. The two-week record must be divided before the station data can be merged with that of the rest of the network. At present, data from the HGLP, SRO, and ASRO networks are first processed by the Albuquerque Seismological Laboratory (ASL), operated by the U.S. Geological survey, and then forwarded to the Seismic Data Analysis Center (SDAC) for distribution. The Panel recommends that the ASL continue to carry out the basic quality control of incoming digital seismic data. If SDAC is unable to continue the long-term distribution of digital data, then ASL should assume the responsibility for merging all daily station data onto a single file or so-called network-day tape.

DATA HANDLING AND PROCESSING

There are two basic ways to store digital seismic data, and the choice between them depends largely on the methods by which users may access the archives.

The simplest method of storage is to retain the networkday tapes. Data from the HGLP, SRO, and ASRO networks are expected to generate between one and two standard $\frac{1}{2}$-inch reels of tape per network day. Addition of other seismic data may increase this to three or four reels per day, totaling about 1000 tapes per year from the integrated network. This is not an excessive number of tapes, and they could be stored relatively easily.

The use of a computer-mass-storage device would provide a much more sophisticated and flexible system. Such a device, the Dataçomputer, is now being used by the Computer 
Corporation of America, under the sponsorship of the Defense Advanced Research Projects Agency. Storage is on high-speed video-tape devices with on-line capacity between $10^{11}$ and $10^{12}$ bits and virtually unlimited off-line capacity. The advantage of this system is that access to complex file structures is included in the softwave support system and data can be retrieved according to the requirements of the usex. In particular, the system will be able to generate an event-associated series of waveforms, as well as bulletin information. On the other hand, in a system that relies heavily on bulletin production, extensive processing is necessary in order to make the proper associations.

From the point of view of archiving, both systems are equally valid. Both suffer the problems of magnetic-tape storage, and the problem of tape life, in particular, should be examined carefully, whichever system is adopted.

The distribution of analog data is carried out by EDS. Users request by mail copies of the data contained in the archives, usually in microfilm form, and the copies are supplied at a nominal cost. The Panel recommends longterm funding to permit the continuation of this service.

Three ways a user can obtain access to the digital-data collection are described below.

1. Computer Storage and Retrieval. If all seismic data are stored on a computer-mass-storage device in an event-associated form, access to the mass store will be by computer network (such as the ARPANET). Users with computers directly linked into this network would be able to retrieve directly (in a read-only mode) from the archives. Other users could use standard telephone connections to obtain a slow-rate data access. One user with a direct connection to the mass store would be EDS, which would make up data tapes according to user requests and mail copies to users for a nominal charge.

2. Network-Day Storage with User Services. In this mode of operation, all steps in the processing and distribution would be handled by EDS. Archival storage would consist primarily of network-day tapes. EDS would have enough computational facilities and staff to respond to a variety of user requests. For example, waveforms for a specific event could be selected from the archives and made into a tape in a format compatible with the users' processing facilities. It is anticipated that eventassociated tapes could be made up on a regular basis for particularly interesting or large events. 
3. Network-Day Storage Only. In the simplest methods, EDS would store network-day tapes and duplicate them on request.

Selection between these alternatives must be based on funding. Option 1 is clearly the most efficient for all users, although it is also the most expensive. Option 2 would be adequate for many purposes, although the time between user request and data receipt might be extensive at times. Option 3 is, in our opinion, generally inadequate. The costs of options 1 and 2 should be examined in detail, along with the advantages and disadvantages of each.

A summary of current network data handling, described in part above, is presented schematically in Figure 16.

\section{THE NEED FOR REGIONAL RESEARCH CENTERS}

Developing competence in the use of digital data within the user community is of prime importance. Conventional NSF support, based on good research proposals, is needed for analysis of digital data. There will be a need to inform and to create interest among potential users of digital data; this can be done at symposia and in other ways.

The most promising areas of digital seismic research require the development of certain basic software. One way to meet this problem would be to take advantage of the experience already gained at several institutions across the country by encouraging other workers to visit these institutions and learn first hand what can be done with digital data.

The Panel recommends that several geographically distributed Regional Research Centers be established. These Centers would have the following characteristics:

(a) Each would have a library of digital seismic data.

(b) Each would have access to extensive computing facilities.

(c) They would develop a variety of software for the manipulation, display, and processing of digital seismic data.

(d) Their staffs would include programmers, analysts, and research seismologists (either at the institution or in the immediate area). 
original SEISMOGRAMS

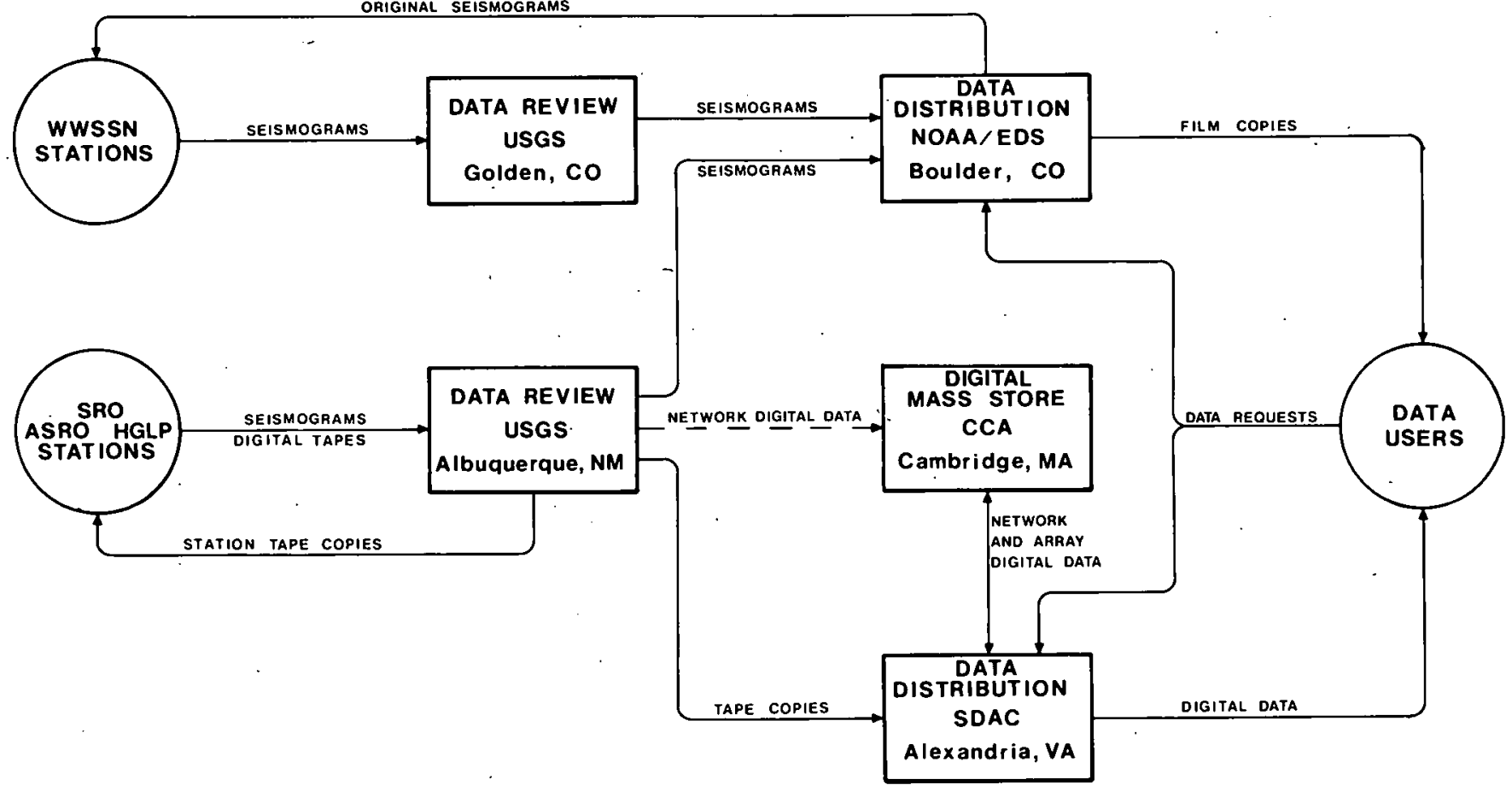

FIGURE 16 Diagram showing the flow of network data from the stations to the data users. (U.S. Geological Survey, Jon Peterson.) 
(e) They would encourage visitors to spend periods ranging from a few weeks to a few months working with their staffs on research problems.

Institutions with these characteristics already exist. Examples include the following: on the East Coast, the Lincoln Laboratory of the Massachusetts Institute of Technology, the Lamont-Doherty Geological Observatory, and the Seismic Data Analysis Center; on the West Coast, the University of California at San Diego and at Berkeley and the California Institute of Technology; and, in the Boulder Colorado, area, EDS together with nearby universities. Th Panel suggests that several of these institutions be designated as Regional Research Centers and that interagency support be provided to maintain their capability to receive and help visiting scientists. This approach could eliminate or reduce the unnecessary duplication of hardware and software facilities that might accompany widespread use of digital seismic data.

\section{USER SERVICES}

Routine services such as the Preliminary Determination of Epicenters (PDE) and the International Seismological Centre (ISC) bulletins currently use seismological techniques that are little changed since the 1930's except for the adoption of digital computers to process large amount of data rapidly.

The impact of the new digital-data base on the science and on its capacity to serve the community will be immense. For example, an analyst might use a display device to catalogue waveforms for event parameters. Such operations as spectral analysis of body- and surface-wave phases, narrowband and matched filtering, rotation and combination of components, comparison of events in an aftershock sequence, and time-frequency analysis of short-period signals can be performed quickly and easily. It is also possible to automate the timing of first arrivals and the identification of secondary arrivals. Once digital data are at hand, the techniques are computationally simple to estimate routinely the depths of the hypocenters of most earthquakes to within a few kilometers, and with that information to refine the hypocentral parameters further.

We now have the opportunity to estimate routinely not only where stress is released in the earth but also how it is released. It is desirable that the possibility of routine determination of certain source parameters, such as 
moment tensor, be considered. Existing analytical methods can be used to estimate such parameters as direction of rupture propagation, fault length, and seismic moment. Such analysis probably could be routinely applied now to all events of $M_{S}>6$ and perhaps as low as 5.5. Even if present models are wrong, we will have the parameters with which to reproduce the seismograms and thus to establish new. models.

The production of a first-rate earthquake catalogue is essential to the seismological community, not only for statistical studies but as a means for even-associated archiving of waveform data, including digital data. The best input data for the production of such a catalogue would be that from a primary network of accurately calibrated, competently operated, digital-recording stations with good geographical distribution. The availability of digital data in a standard format carries the promise that a certain amount of information can be processed routinely and included in the bulletins of seismological services such as the ISC and the National Earthquake Information Service of the USGS.

Further refinements in seismological services should come from intensive research, as more data become available. such research should be undertaken as soon as possible.

A. The Panel recommends continuation and improvement of user services such as the PDE program and the ISC Bulletin and the reporting of additional event parameters.

$B$. The Panel recommends initiation of a program of intensive research to determine what impact the new digitaldata base will have on user services and in what ways the new services can be implemented. 
9. SUPPORT FOR THE IMPROVED WORLDWIDE
STANDARDIZED SEISMOGRAPH NETWORK

Support for the components of this improved network has been discussed throughout this report. The following budget presents proposed costs for operating, improving, and performing research and development in the order of priority that the panel considers appropriate in order to take advantage of all new developments in the field. This improved WWSSN would provide vast opportunities for new discoveries as a direct result of its upgraded instrumentation, of improved station distribution, and of the superiority of its digital data base over past data systems. The improved WWSSN should not be static but should change with the needs of the investigators in their search for new knowledge and for answers to many scientific questions.

To this end, the Panel recommends that the status of the global earthquake monitoring system be reviewed every five years to determine whether it is adequately meeting the needs of its users.

\section{Budget for the Improved Worldwide Network (\$ Thousands)}

\section{PRIORITY I}

Upgraded WWSSN--includes present WWSSN stations and HGLP, SRO, ASOR, and IDA stations.

\section{One-Time Expenses}

A. Upgrading of data-processing facilities to produce network-day tapes

B. Upgrading of data storage and processing facilities to provide services for digital data bank 


\section{Operating Expenses}

A. Personnel and overhead (includes 4 traveling technicians to visit each station every 2 years)

B. Data review and preparation of networkday tapes

c. Copying, archiving, and distribution of analog and digital data

D. Other expenses, including repair and supplies

\section{PRIORITY II}

Additional required upgrading of WWSSN-conversion of 50 conventional WWSSN stations to digital recording and other needed improvements.

\section{One-Time Expenses}

A. Equipment, instaliation, and development 1450

\section{Operating Expenses}
A. Personnel, data review, preparation of network-day tapes, and other expense
B. Copying, archiving, and distribution of data

Two-year. research effort to determine the feasibility of an extensive long-term program in ocean-bottom seismology, to include the use of three-component, broadband seismographs 
Additional upgrading of WWSSN

\section{One-Time Expenses}

Acquisition of 10 portable digitally

recording broadband seismographs at $\$ 75,000 /$ station

\section{Operating Expenses}

A. Personnel (4 technicians and 7 professionals) for installation of equipment at different locations around the world (6 mo/yr at $\$ 15,000 / \mathrm{mo})$

B. Equipment maintenance, transportation, travel, and supplies

At least 14 federal agencies depend on seismological information in the discharge of their public obligations. In turn, the government is responsible for seeing that such information is made available to those who need it. For example, many government agencies and industrial and business groups require earthquake statistics on a national or international basis for the analysis of seismic risk and in their efforts to resolve a multitude of other problems. If these needs for information are to be met, seismological observations must be obtained from adequate national and international networks over long periods of time, and it must be a government function to acquire, process, and disseminate these data. In addition, a basic requirement of all mission agencies, and one that must be assumed by the federal government, is for a general body of scientific knowledge that can be drawn upon when needed: that is, for a broad data base built up painstakingly over the years through the work of many individual scientists in cooperation with their colleagues in many parts of the world. In the next decade, there must be continuing maintenance of the present basic U.S. capability in observational seismology. In addition, the growing demands for risk mapping and for information vital to nuclear-power-plant siting, the expected expansion of population, and the growing capability for earthquake prediction make updating of instrumentation and data-analysis techniques mandatory. 
The Panel recommends that mechanisms be established in the federal government to ensure sufficient and appropriate funding, within the USGS for uninterrupted operation and timely upgrading of these most basic facilities and services and within NOAA/EDS for the seismogram and digitaldata organization, distribution, and services.

The Panel also recognizes the responsibilities of other government agencies in this endeavor and further recommends that the responsibility for formulating this plan be vested in an interagency initiative. Clearly, a stable budget must be established within the federal government to provide the necessary very long-term funding of seismological networks.

A number of major industries benefit directly and substantially from new knowledge gained through seismological research. Among these are the petroleum, electric power (nuclear), and housing (land use) industries; mining and quarrying; the construction industry; and insurance companies. The kinds of data provided by global networks of seismographs may seem far removed from the needs of some of these enterprises, but if the potential contribution of seismic network data to their needs is made known to the leaders of these industries, their active support of a global earthquake recording system could contribute significantly to its future development. This support could take the form of direct grants by the companies in support of network activities. For example, grants to universities that would enable them to purchase complete sets of seismogram copies could help to make the EDS Data Center more nearly self-supporting and would be of great value to the research groups.

Perhaps the most critical element in this plan is management. In the years ahead, vigorous and imaginative management will be essential to the growth and continuing development of the WWSSN and its data-dissemination facilities. The most desirable plan would be for permanent assignment of management oversight of the network to an interagency group, with all agencies that use the data providing management guidance through the group. It is essential that responsible government officials recognize that the systematic collection of worldwide seismological data is as much in the national interest as, for example, the routine acquisition of weather data. 


$\quad$ THIS IPAGE
WAS INTENTIONALIY
$\because \because$ LETT BLANK




\section{BIBLIOGRAPHY}

Agnew, D., J. Berger, R. Buland, W. Farrell, and F. Gilbert (1976). International Deployment of Accelerometers: a network of very-long-period seismology. E $\oplus S$, Trans. Am. Geophys. Union 57, 180-188.

Geophysical Data Centers: Impact of a Data-Intensive Program (1976). Report of the Geophysical Data Panel of the NRC Committee on Data Interchange and Data Centers.

Oliver, J., and L. Murphy (1971). WWSSN: Seismology's global network of observing stations. Science 174 , 254-261.

Peterson, J., and N. A. Orsini (1976). Seismic Research Observatories: upgrading the world-wide seismic data network. EAS, Trans. Am. Geophys. Union 57, 548-556.

Peterson, J., H. M. Butler, L. G. Holcomb, and C. R. Hutt (1976). Seismic Research Observatory, Bull. Seismol. Soc. Am. 66, 2049-2068.

Predicting Earthquakes: A Scientific and Technical Evaluation--with Implications for Society (1976). Report of the Panel on Earthquake Prediction, NRC Committee on Seismology. National Academy of Sciences, Washington; D.C.

Report of the Ad Hoc Panel on the Worldwide Standardized Seismograph Network (1969). NRC Committee on Seismology. Savino, J., A. Murphy, J. M. Rynn, R. Tatham, L. Sykes, G. Choy, and K. McCamy (1972). Results from the highgain long-period seismograph experiment. Geophys. J. R. Astron. Soc. 31, 179-204.

Trends and Opportunities in Seismology (1977). Report of a workshop convened by the NRC Committee on Seismology. National Academy of Sciences, Washington, D.C. 


\section{THIS PAGE}

WAS, INTENTIONALLY

LEFT" BIAANK 
GLOSSARY

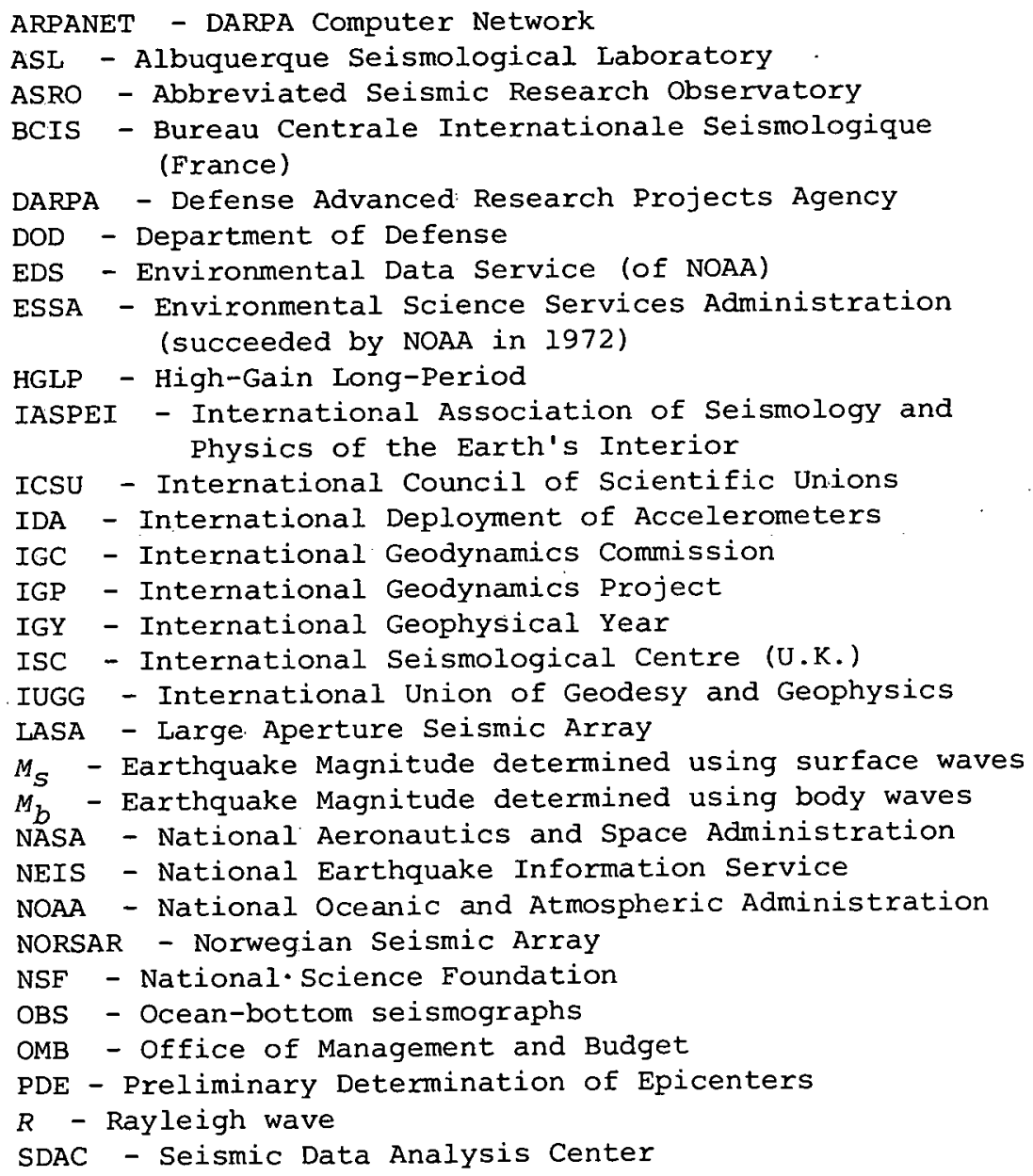


S/N - Signal-to-noise ratio

SRO - Seismic Research Observatories

$T$ - Period (time domain)

USGS - U.S. Geological Survey

WDC - World Data Center

WWSSN - Worldwide Standardized Seismograph Network. (or Worldwide Network of Standardized Seismograph Stations) 
APPENDIX A

RESEARCH DIRECTIONS

What kinds of global seismological studies are foreseen over the next decade?. What could be the effect of a readily available, global, high-quality digital-data base? What research needs may still not be met by an integrated global system? This appendix attempts to answer these questions and to develop a rationale, based on research potential, for an optimum global data-acquisition and distribution system.

Data from the integrated global network should be of sufficiently high quality to permit refined resolution of both global and regional earth structures. Well-calibrated instruments would enable the use of amplitudes of longperiod waves and oscillations and of short-period pulses. The amplitude data are valuable for the study of both source mechanisms and structures and offer the possibility of improving our knowledge of seismic-energy dissipation. Further improvement in the identification of normal modes will be made possible by the expanding network of broadband stations. The short-period data could be important in reducing the reading error in travel-time studies and in the identification of depth phases. High-quality data of wide dynamic range could be essential in the identification of multiple events accompanying large earthquakes and could lead to a bettex understanding of the propagation of rupture along a fault.

Data from the global network would be used primarily in studies of earthquakes from far-field displacements and in investigations of earth stxucture. In general, these two objectives cannot be separated, since our ability to infer properties of a source from seismic recordings is limited by our knowledge of the mechanical properties of the medium (earth structure). In recent years, significant progress in the theoretical and numerical aspect of 
earthquake-mechanism studies has greatly increased our qualitative understanding of the physical properties involved in naturally occurring faulting. Concurrent advances in the calculation of synthetic motion by a given source excitation embedded in realistic earth models provide a powerful tool to a fuller understanding of the considerable complications of actual seismograms and to separate complexities of the source from those arising from the propagation of the disturbance in a heterogeneous earth. In other words, seismologists want to explain observed motions on a global scale in terms of the source after separating out those effects associated with propaga tion. The solution of this basic problem is probably essential to an understanding of local strong motions, which, in turn, is needed in testing the dynamic response of critical structures (e.g., nuclear reactors) and in the general estimation of ground motion of engineering interest. Secondly, a better appreciation of earthquake characteristics such as depth, dimension, and stresses is essential to a clearer understanding of the conditions that exist in fault zones and thus is an aid in earthquake prediction.

If we assume that the ground motion at the recording site following an earthquake can be derived from a seismic recording by removing the effect of instrumental response, then the motion is determined by two factors: the seismic source and the mechanical structure of the earth through which the seismic waves pass. Obviously, to make inferences about the source we must have a model of the medium (the earth). Thus, studies of source properties cannot be detached from measurements of propagation effects. The next stage would be the use of inversion models of the source and the medium, using modern methods. We may then generate synthetic data and compare them with observations. The differences will suggest inadequacies in our model of the medium (for example, those due to the effect of lateral heterogeneities) or of the source. Phase-equalization techniques can be used to provide initial information about the source mechanism, which, in turn, can be used to improve our knowledge of the medium. With the improved model of the medium we may repeat inversion for the source mechanisn What has been described is actually an iterative, selfimproving process of learning. Source physics is one of the least understood areas of seismology, and by this process we hope to gain further insight.

The advent of digital computers has significantly broadened our ability to pull useful information out of 
the data base used in seismological research. The first observations of free oscillations of the earth following the Chilean earthquake of May 22, 1960, are a good example. To take advantage of this computer capability it is necessary, however, to represent the time series in numerical form. In a vast majoxity of cases, conversion from analog data to digital data has been achieved by manual operation. This process is time-consuming and not very accurate, and the small dynamic range of analog recordings represents a serious limitation on the magnitude span of events that can be analyzed in this way. Nevertheless, application of numerical methods to time-series analysis has led to significant progress in our knowledge of longperiod characteristics of seismic sources, average properties of the earth, and regional variations in surfacewave dispersion. The advantages of using digital data in body-wave studies have been well illustrated by the results obtained from seismic arrays such as the Large Aperature Seismic Array (LASA) and the Norwegian Seismic Array (NORSAR).

To achieve our goal of inferring quantitatively the spatial and temporal distribution of stress release at depth requires detailed modeling of broadband observations, recorded on a global scale because of the complexity of the problem. Observations obtained from the WWSSN have been used almost exclusively in such analyses in recent studies. The existence of a worldwide broadband network of seismological instruments with digital recording capabilities would mean that many new and currently available analytical methods could yield more accurate results than have been possible thus far and could be applied on a routine basis to a great many events. This does not mean that we underestimate the significance of the data recorded by analog systems. Much of the excellent seismological research of the last decade testifies to the success of the WWSSN, and its continued operation is considered essential. The following is a discussion of opportunities to apply digital data from a global network to studies of source mechanisms and of mechanical properties of the earth.

For wavelengths greater than about six times the largest source dimension, the source can be treated as a point in space. A detailed treatment of the concept of representing the properties of a seismic source in terms of the moment tensor and a description of the phase-equalization techniques can be found in J. F. Gilbert and A. Dziewonski (Phil. Trans. Roy Soc. London A278, 187-269, 1975). The 
source is characterized by the volume integral of the stressrelease mechanism, the moment tensor, or the moment-rate tensor as a function of time. With $M_{S}>7$, ten global stations can be used to infer the moment-rate tensor by a linear inversion procedure. The moment-tensor approach is not limited to large earthquakes that generate free oscillations. It can also be used in the traveling-wave formulation applied to analysis of any chosen portion of a seismogram. The relevant theory exists, and the numerical methods are rather straightforward.

Let us define a seismic-moment-rate spectrum as one tha ${ }^{-}$ is flat. In this case, the source-time function is a ster function. There is considerable evidence from body waves, surface waves, and free oscillations that actual moment-rate spectra can exceed the seismic sprectra at either end of the frequency range. Some earthquakes are rich in high frequencies ("ultraseismic" events), and these need not be small earthquakes only. Others are rich in low frequencies ("infraseismic") and may approach being "aseismic"--that is, they have so little high-frequency energy that they are unobservable on traditional seismographs. An extreme example of the latter is creep. Global data are essential to determine whether any seismic activitiy exists at energy levels between those of creep and of infraseismic events, to examine ultraseismic events more carefully, and to determine how earthquakes begin.

The point source is the simplest possible representation of a seismic event, and it is a good approximation above a certain range of wavelengths, that is, at periods significantly greater than the rupture-propagation time. Also, approximation of the physical charactex of the earth by a radially symmetric average earth model is better at long periods. If we consider surface waves as an example, the great-circle-path phase velocities of Rayleigh waves differ by no more than 1-2 percent in a period range of $150-300$ sec. At a period of about $40 \mathrm{sec}$, the differences can be as great as 15 percent and the effect of regional variations cannot be discarded in an attempt to resolve source properties. Studies of infraseismic events and surface waves require the long-period instrumental response to be as high possible.

At wavelengths so short that the point-source approximation is not valid, it is necessary to investigate the volume density of the dislocation mechanism. To do this, we must consider the moment-density tensor, which has dimensions of stress, as a function of time. Thus far, nearly all studies of the moment-density tensor have 
depended on assumed characteristics of the source mechanism. It is almost a tradition to assume the form of the sourcetime behavior, constant rupture-propagation velocity, and fixed nodal planes. It is probably inevitable that some degree of a priori parameterization of the source-mechanism will be needed, and the advent of the global digital network will help in the refinement of such parameters as rupture-propagation velocity and source-time behavior. There is a need for more fundamental investigations of the nature of distributed sources.

The solution of this basic problem, of explaining observed motions on a global scale in terms of the source and propagation effects, is probably essential to the understanding of local strong motions and, hence, in the general estimation of ground motion of engineering interest. This is especially important to the USGS Earthquake Hazards Reduction Program. Near-field measurements of earthquakes with sufficient strength to be recorded globally are essential to this approach.

Teleseismic body-wave travel times, the periods of free oscillations, and the dispersion characteristics of very long-period surface waves have traditionally been interpreted in terms of a spherically symmetric model of the earth. Now, the differences among such models are quite small, except for the upper mantle. Actually, the concept of a spherically averaged upper mantle probably may be of limited geophysical interest, even though it is mathematically useful. More recently, considerable evidence has been gathered to support the idea that aspherical structures exist as deep as the core-mantle boundary. Nevertheless, a spherically symmetric earth model is a very good approximation, as such a model is capable of explaining some 99.9 percent of the values of observed normal modes. However, for a rotating, laterally heterogeneous earth, a normal mode of angular order, 1 , is split into $21+1$ spectral lines in the generally distinct but only slightly different eigenfrequencies. The complex amplitude of each spectral line depends on the location of the source and receiver, the earth's heterogeneity, and the souxce mechanism. Such a line convolved with the resonance curve (determined by $Q$ of the mode) represents a "singlet." What we observe in a spectrum of an individual seismogram is a "multiplet," the result of superposition of $21+1$ singlets. Thus, the next step would be to resolve the fine structure of spectral peaks. It is a difficult problem, as a reasonable good starting model of a laterally heterogeneous earth is necessary so that phase-equalization procedures can be applied. 
For a phase-equalization procedure to be successful, it is necessary to predict for each receiver the amplitude of the mode to be extracted, and this amplitude depends also on the earth's heterogeneity. Thus, global studies of lateral heterogeneities using surface waves and body waves are prerequisite to superresolutions (extraction of singlets from multiplets) of the normal-mode spectrum. The rewards, however, would be significant. If we could isolate singlets, we could measure the anelastic attenuation, separated from the effects of elastic scattering. The eigenfrequencies of singlets would represent a new class of data that could be used in construction of threedimensional earth models.

Despite some current difficulties caused by splitting, observations of free oscillations are the best tool for estimating source properties at very long periods.

The distinction between surface waves, or even body waves, and normal modes is a matter of practice rather than theory. At sufficiently short wavelengths, the raytheory approximation (in which the propagation effects are. assumed to be associated with a particular ray path rather than with global properties of the earth) comes close enough to reality that assumption of its validity might lead to useful starting solutions. Much of what is assumed about the differences between upper-mantle structures under oceans and under continents comes from the "pure path" dispersion studies. If reliable phase-velocity data should become available for "fractional" paths $\left(R_{1}\right.$ or $\left.R_{2}\right)$, an inversion for the global three-dimensional structure of the upper mantle could be attempted. Knowledge of the lateral differences in phase velocities could be used to improve the precision with which source parameters are determined.

At short periods $(T<100 \mathrm{sec})$, the effect of lateral variations in structure becomes very pronounced; also, the effect of multipathing can be significant, particularly in amplitude measurements. In recent years, numerous attempts have been made to measure "single-station" phase velocities, estimating the initial (source) phase shift from the fault-plane solution. It is possible to supplement this method by determining the source geometry from the long-period data, as previously discussed, and establishing a library of "master events" with known phasedelay characteristics; these could then be used to determine the source parameters of small-magnitude events that have not generated long-period surface waves of sufficient amplitude. Perhaps the iterative nature of the studies of 
source mechanism and earth structure may find its most extensive application in studies of the dispersion characteristics and excitation of short- and intermediate-period surface waves.

Long-period body waves can be used in the sourcemechanism studies in much the same way as surface waves or free-oscillation data. It is possible to generate synthetic seismograms corresponding to each of the six elements of the moment tensor and then determine their components by inversion. The advantage of this procedure may be that in a given period range--say, 30-50 sec--the body waves will show much less regional variation. Combining the normalmode approach with one of several generalized ray methods may be optimal, as these two different approaches are most efficient in different frequency ranges.

Body-wave data are important for accurate hypocenter location. Among the first-order source parameters, the least well determined is focal depth. More than three quarters of all earthquakes occur at depths of less than $70 \mathrm{~km}$; for more than half of these shallow earthquakes, the depth can be determined with a minimum error of $\pm 25 \mathrm{~km}$. This large imprecision results mainly from the tradeoff between origin time and focal depth that occurs when the hypocenter is determined from teleseismic travel times. If the origin time were accurately fixed, the depth could be determined to approximately $l$ sec of $p$-wave travel time at crustal velocities and vice versa. To fix the origin time, observations of $S-P$ for distances less than about $10^{\circ}$ of arc are required. Even with the most advantageous placement of, for example, a 30-station network, a great number of earthquakes would still lie beyond the required range. Hence, precise determination of focal depth will depend on the observation of near-source surface reflections, $p P$, $s P, p P C P, S P C P$, etc. Direct observation of the delay times of these phases can fix the depth to within several kilometers. Since the delay time for near-source reflections is less than about $20 \mathrm{sec}$ for earthquakes occurring in the crust, the arrival time and even the presence of the phase itself will often be obscured by the waveform of the primary phase. Recent work on improvements of homomorphic deconvolution and cepstral analysis might be useful in routine estimation of focal depth under those circumstances. Other innovations include making use of maximum-entropy spectral analysis of the log spectrum and spatial and temporal averaging of spectra to enhance depth-phase peaks. Lowpass filtering of short-period seismograms before analysis should allow depth-phase detection where the roughest topography exists. 
Another important area of investigation is that of coda waves; these waves -include information on both the earthquake process and earth structure. Separation and resolution of these two effects require the availability of a vast amount of data for different sources and stations. Finally, there are studies that require strategic instrumental coverage and therefore depend on the favorable occurrence of earthquakes from certain sources. Examples include studies of aftershocks; upper-mantle, core-mantle, and inner-core structures; absorption; diffracted waves; and geothermal research.

Some operational aspects of the global seismograph network are relevant to research opportunities described above. If WWSSN data are used to infer the momènt rate tensor by linear inversion, the errors are about 10 percent or worse. A global digital network should permit the inference of source mechanisms for smallex value of $m_{b}$ as the number of stations increases and as the signal-tonoise ratio ( $\mathrm{S} / \mathrm{N})$ improves. For WWSSN instruments, the $\mathrm{S} / \mathrm{N}$ is rarely more than $20 \mathrm{~dB}$. Digitization noise, caused by the finite and sometimes large width of the signal trace, and signal-generated noise, caused by as yet unknown instrumental nonlinearities, are mainly responsible. The newer digital instruments appear to have a $S / N$ of over 100 dB for events with $M_{S}>7$, but there remains considerable work to be done before their calibrations are well understood.

The average noise level of a single instrument should not be necessarily taken as a cutoff level. Availability of a large network of instruments and application of phaseequalization techniques can result in a significant improvement of the network $\mathrm{S} / \mathrm{N}$. Studies of infraseismic events also require the long-period response to be as high as possible.

Perhaps the word "global" with respect to seismic instrumentation should be understood not only in the sense of geographical distribution but also in the sense of the frequency band of measurements. We have mentioned earlier the "infraseismic" events, those that are characterized by anomalously high spectral values of the moment rate tensor at very long periods. This is related to the difficult but important problem in geodynamics of whether plate slip is continuous or discontinuous. Although it is likely that the currently deployed, or being deployed, network of in'struments may be material in the identification of infraseismic events, there is an urgent need for construction and worldwide application of instruments with 
the necessary zero-frequency response. Measurements of this type are currently planned by NASA, but it seems likely that they should be supplemented by a network of high-class strainmeters that would provide continuous monitoring of the state of stress in the crust. It is important that these instruments be standardized, to make possible correlation of the data from various sites.; 


\section{APPENDIX B \\ INTERNATIONAL COMMENT ON THE WORLDWIDE STANDARDIZED SEISMOGRAPH NETWORK: INTEGRATED NETWORKS AND USER SERVICES}

In December 1975, a letter on behalf of the Panel on Seismograph Networks was sent to the President of the International Association of Seismology and Physics of the Earth's Interior (IASPEI) and to the President of the Interunion Commission on Geodynamics. The letter explained the charge to the Panel and requested comments from the international seismological community regarding the value of the Worldwide Standardized Seismograph Network (WWSSN) to the community and ways in which potential upgrading of the WWSSN and the collection and dissemination of data might best meet the research requirements of major scientific problems.

This letter was distributed by the Secretary General of IASPEI to all national correspondents, and replies have been received from national correspondents of 17 countries. While several of the correspondents presented the letter to the National Committee of their country, the majority of the correspondents replied directly; the following is a summary of their main comments:

1. There was general endorsement of the WWSSN, which was viewed as a key ingredient in seismology's future. The significant contributions made by WWSSN data were recognized.

2. Upgrading the WWSSN would be of international importance. Furthermore, maintaining analog records remains necessary for use by some countries that do not have facilities to process digital data.

3. A network providing a broadband digital data base would provide new research opportunities to seismologists; the future of seismological studies lies with this type of data base. 
4. The user community should have convenient and easy access to any new digital-data base and computer facilities.

5. It is important to supplement any new network capability with more adequate "routine services" [Preliminary Determination of Epicenters (PDE), for example]. 